\title{
ATP Excites Interneurons and Astrocytes to Increase Synaptic Inhibition in Neuronal Networks
}

\author{
David N. Bowser and Baljit S. Khakh \\ Medical Research Council Laboratory of Molecular Biology, Cambridge CB2 2QH, United Kingdom
}

We investigated the role of extracellular ATP at astrocytes and inhibitory GABAergic interneurons in the stratum radiatum area of the mouse hippocampus. We show that exogenously applied ATP increased astrocyte intracellular $\mathrm{Ca}^{2+}$ levels and depolarized all calbindinand calretinin-positive interneurons in the stratum radiatum region of mouse hippocampus, leading to action potential firing and enhanced synaptic inhibition onto the postsynaptic targets of interneurons. Electrophysiological, pharmacological, and immunostaining studies suggested that the effect of ATP on interneurons was mediated by $\mathrm{P}_{2} \mathrm{Y}_{1}$ receptors, and that the depolarization of interneurons was caused by the concomitant reduction and activation of potassium and nonselective cationic conductances, respectively. Electrical stimulation of the Schaffer collaterals and perforant path, as well as local stimulation within the stratum radiatum, evoked increases in intracellular $\mathrm{Ca}^{2+}$ in astrocytes. Facilitation of GABAergic IPSCs onto interneurons also occurred during electrical stimulation. Both the stimulation-evoked increases in astrocyte $\mathrm{Ca}^{2+}$ levels and facilitation of GABAergic IPSCs were sensitive to antagonists of $\mathrm{P} 2 \mathrm{Y}_{1}$ receptors and mimicked by exogenous $\mathrm{P}_{2} \mathrm{Y}_{1}$ receptor agonists, suggesting that endogenously released ATP can activate P2Y receptors on both astrocytes and interneurons. Overall, our data are consistent with the hypothesis that ATP released from neurons and astrocytes acts on $\mathrm{P}_{2} \mathrm{Y}_{1}$ receptors to excite interneurons, resulting in increased synaptic inhibition within intact hippocampal circuits.

Key words: purinergic; interneuron; astrocyte; inhibition; IPSP; hippocampus; P2Y; P2X

\section{Introduction}

Increasing evidence suggests that astrocytes actively participate in synaptic and neuronal function as well as fulfill their classical supportive roles in the brain (Fields and Stevens, 2000; Haydon, 2001; Fields and Stevens-Graham, 2002; Newman, 2003a). Astrocytes release gliotransmitters into the extracellular space that may then activate receptors on nearby neurons (Araque et al., 2001). ATP functions as an extracellular signaling molecule (Zimmermann, 1994; Burnstock, 2004), and recent work suggests that ATP is also a gliotransmitter. Once released from a point source, ATP may trigger a wave of astrocyte excitation that can travel hundreds of micrometers (Guthrie et al., 1999; Haydon, 2001; Newman, 2001a,b, 2003a). Recently, glial ATP has been shown to decrease the excitability of neurons in the retina (Newman, $2003 \mathrm{~b}$ ) and mediate presynaptic modulation in cultured hippocampal neurons (Koizumi et al., 2003; Zhang et al., 2003). An important unresolved issue, however, is whether endogenously released glial ATP actually regulates the excitability of brain neurons in networks with functionally preserved connectivity (Hay-

Received March 30, 2004; revised Aug. 17, 2004; accepted Aug. 18, 2004.

This work was supported by the Medical Research Council (UK), European Molecular Biology Organization (EMBO) Young Investigator Program, Human Frontier Science Program, and an EMBO Long Term Fellowship to D.N.B. We are indebted to Drs. Elizabeth Maywood and Michael Hastings for advice on immunostaining and for use of the cryostat. We thank Drs. Stephen Williams and Terrance Egan for comments during early stages of this study, Dr. Brad Amos for help with setting up the confocal microscope, and Dr. Bazbek Davletov for the gift of botulinum toxin. We also thank the mechanical workshop staff for all their help.

Correspondence should be addressed to Baljit S. Khakh, Medical Research Council Laboratory of Molecular Biology, Hills Road, Cambridge CB2 20H, UK. E-mail: bsk@mrc-Imb.cam.ac.uk.

DOI:10.1523/JNEUROSCI.2660-04.2004

Copyright $\odot 2004$ Society for Neuroscience $\quad$ 0270-6474/04/248606-15\$15.00/0 don, 2001). In this report, we present evidence to suggest that endogenously released ATP can affect the function of nearby astrocytes and interneurons within the stratum radiatum (s.r.) and stratum lacunosum-moleculare (s.l-m.) regions of the mouse hippocampus.

A role for extracellular ATP as a signaling molecule in the nervous system was first proposed over 30 years ago (Burnstock, 1972). Extracellular ATP acts on two families of receptors, P2X and $\mathrm{P} 2 \mathrm{Y}$ receptors. $\mathrm{P} 2 \mathrm{X}$ receptors are $\mathrm{ATP}$-gated nonselective cation channels that are found throughout the body (Khakh, 2001), whereas P2Y receptors are seven transmembrane domain receptors that couple to G-proteins (Lazarowski et al., 2003) and in some cases directly to channels (O'Grady et al., 1996; Lee et al., 2003). P2Y receptors comprise a family of at least eight members; they couple to Gq and Gi proteins and thus activate phospholipase C and inhibit adenylyl cyclase (Lazarowski et al., 2003). In relation to other transmitter receptor families, the functions of $\mathrm{P} 2 \mathrm{Y}$ and $\mathrm{P} 2 \mathrm{X}$ receptors in the brain are not well understood, and one important goal is to decipher how ATP affects brain neurons through the interplay of $\mathrm{P} 2 \mathrm{X}$ and $\mathrm{P} 2 \mathrm{Y}$ receptor signaling.

Inhibitory GABAergic interneurons have small range projections within the hippocampus and constitute a diverse group of neurons (McBain and Fisahn, 2001). S.r. interneurons in the CA1 region of the hippocampus receive inhibitory innervations from other local interneurons and form GABAergic synapses onto output pyramidal neurons to mediate feedforward IPSPs. By receiving excitatory input from CA3 neurons and evoking inhibition of interneurons and output CA1 pyramidal neurons, s.r. interneurons profoundly affect network activity within circuits (McBain and Fisahn, 2001). Astrocytes are abundant in the hippocampus; 
their processes profusely interleave between synapses in the s.r. (Ventura and Harris, 1999). However, the possibility that astrocytes may regulate interneuron excitability has remained unexplored. In the present study, we provide evidence for a novel ATP-mediated excitatory response in interneurons, which draws on neurons and astrocytes, leading to increased synaptic inhibition in interneuron networks.

\section{Materials and Methods}

Preparation of brain slices and electrophysiological recording. The methods used have been described previously (Khakh et al., 2003). Briefly, young [postnatal day 13 (P13) to P18] C57 mice were killed in accordance with home office and local procedures. Coronal slices of hippocampus (200 or $300 \mu \mathrm{m}$ ) were cut (model 1000 Plus; Vibratome, St. Louis, MO) and submerged at room temperature in artificial CSF ( $\mathrm{aCSF}$ ) comprising the following (in mM): $126 \mathrm{NaCl}, 2.5 \mathrm{KCl}, 1.3 \mathrm{MgCl}_{2}, 10 \mathrm{D}$-glucose, $2.4 \mathrm{CaCl}_{2}$, $1.24 \mathrm{NaH}_{2} \mathrm{PO}_{4}$, and $26 \mathrm{NaHCO}_{3}$ saturated with $95 \% \mathrm{O}_{2}$ and $5 \% \mathrm{CO}_{2}$. Experiments were performed at room temperature or $34^{\circ} \mathrm{C}$ as indicated. Experiments were performed with potassium gluconate or chloridebased internal solution comprising the following (in $\mathrm{mM}$ ): 120 K-gluconate $\left(\right.$ or $\mathrm{Cl}^{-}$), $10 \mathrm{KCl}, 1 \mathrm{MgCl}_{2}, 0.03 \mathrm{CaCl}_{2}, 0.1$ EGTA, $1 \mathrm{ATP}, 0.2$ GTP, 10 HEPES, 4 glucose, $\mathrm{pH}$ 7.25. The resistance of the pipettes was $\sim 4-9 \mathrm{M} \Omega$. Cells were visualized with infrared optics (900 nm; Olympus, Southall, UK) on an upright microscope (BX51; Olympus). Puffs of ATP were applied under visual control using a Picospritzer II (General Valve, Fairfield, NJ). In our previous work, we applied agonists directly to the bath (Khakh et al., 2003) over tens of seconds, but in the present study, we used a fast bath application system (RV-8; Warner Instruments, Hamden, CT), ensuring that oxygenated solutions were applied to the brain slice chamber within $500 \mathrm{msec}$ for complete bath change in $\sim 1.5$ sec. Synaptic currents were recorded in the presence of 6-cyano-7nitroquinoxaline-2,3-dione (CNQX; $10 \mu \mathrm{M}$ ) to block AMPA/kainate receptors. ATP-induced inward currents were recorded in CNQX $(10 \mu \mathrm{M})$, AP-5 (10 $\mu \mathrm{M})$, bicuculline (10 $\mu \mathrm{M})$, and tetrodotoxin (TTX; $1 \mu \mathrm{M})$. The adenosine receptor antagonist cyclopentyl-1,3-dipropylxanthine (DPCPX; $10-100 \mu \mathrm{M}$ ) was always present in the bathing medium and ruled out $\mathrm{P}_{1}$ receptor involvement. The concentrations of agonists and antagonists used are higher than those used in biochemical studies of P2Y receptors because of breakdown and/or penetration barriers that are inherent with brain slice recording (North, 2002). Inward currents were recorded at $-60 \mathrm{mV}$ using pCLAMP 9 software, Multiclamp 900A amplifier, and Digidata 1322A (Axon Instruments, Foster City, CA).

Paired recordings. The whole-cell patch-clamp configuration $(-60$ $\mathrm{mV}$ ) was attained for postsynaptic interneurons and pyramidal neurons with a KCl-based pipette solution containing $1 \mu \mathrm{M} \mathrm{N}$-ethyl bromide quaternary salt of lidocaine to block action currents. Presynaptic interneurons were then patched with a K-gluconate-based pipette solution and held in current-clamp bridge mode. Depolarizing current (100-400 $\mathrm{pA}, 2-4 \mathrm{msec}$ ) was injected in the presynaptic neuron to evoke action potentials and to determine whether it was connected to the putative postsynaptic neuron. If there was no postsynaptic current after 50 trials, the pair was deemed unconnected, the presynaptic neuron pipette was withdrawn, and another presynaptic neuron was sought. This procedure was repeated until connected pairs were found. Consistent with previous work, s.r. interneuron-interneuron connectivity was found in 14 of 67 pairs $(20.8 \%)$, and s.r. interneuron-CA1 pyramidal neuron connectivity was found in 11 of 132 pairs (8.3\%) (Bertrand and Lacaille, 2001).

Confocal imaging of astrocyte activity. Brain slices were loaded at room temperature in the dark with $5 \mu \mathrm{M}$ Fluo-4-AM (Molecular Probes, Invitrogen, Paisley, UK) in aCSF for $60 \mathrm{~min}$ and then transferred to dyefree aCSF for at least $30 \mathrm{~min}$ before experimentation to allow for cleavage of the AM ester group (Porter and McCarthy, 1996). Live astrocytes were predominantly loaded with the fluorescent dye with these conditions. This was confirmed by simultaneous acquisition of infrared differential interference contrast optics (IR-DIC) images of astrocytes in the same area. In some cases, individual interneurons were loaded through the patch pipette with Alexa-488 (50 $\mu \mathrm{M})$ or biocytin $(0.5 \%)$ to approximate neuron shape. Cells and slices were imaged using a Bio-Rad (Ringstead,
UK) MRC-600 laser scanning confocal scan head with attached solid state $5 \mathrm{~mW} 488 \mathrm{~nm}$ laser light source (Laser 2000). Emitted green fluorescence was colleted through a 515 long-pass filter. Bio-Rad CoMOS software was used for image acquisition.

Immunofluorescent labeling in fixed sections. Young (P13-P18) C57 mice were perfused through the heart under deep anesthesia in accordance with home office and local procedures. The perfusate comprised $20 \mathrm{ml}$ of $0.1 \mathrm{M}$ PBS, followed by $50 \mathrm{ml}$ of $4 \%$ paraformaldehyde in $0.1 \mathrm{M}$ PBS (herein called fixative). Blocks of hippocampus, $1 \mathrm{~mm}$ thick, were placed in fixative and left overnight at $4^{\circ} \mathrm{C}$ and then cryopreserved in $20 \%$ sucrose (0.1 M PBS) overnight before cryosectioning (Leica CM3050S cryostat; Leica, Milton Keynes, UK). Free-floating $30 \mu \mathrm{m}$ sections of hippocampus were then extensively washed in PBS, and nonspecific protein binding was blocked by a subsequent incubation in 3\% normal goat serum (NGS) for $2 \mathrm{hr}$. Sections were then incubated in the following primary antibodies: rabbit anti-parvalbumin polyclonal antibody (1:2000, $23^{\circ} \mathrm{C}, 2 \mathrm{hr}$; Abcam, Cambridge UK), rabbit anti-calbindin polyclonal antibody $\left(1: 1000,23^{\circ} \mathrm{C}, 2 \mathrm{hr}\right.$; Chemicon, Hampshire, UK), rabbit anti-P2 $\mathrm{Y}_{1}$ polyclonal antibody $\left(1: 200,4^{\circ} \mathrm{C}\right.$ overnight; Abcam), mouse anti-calretinin monoclonal antibody $\left(1: 50,23^{\circ} \mathrm{C}, 12 \mathrm{hr}\right.$; Abcam), and mouse anti-glial fibrillary acidic protein (GFAP) monoclonal antibody $\left(1: 1000,23^{\circ} \mathrm{C}, 2 \mathrm{hr} ;\right.$ Abcam $)$. All antibodies were prepared in $1 \%$ NGS and $0.3 \%$ Triton X-100 in $0.1 \mathrm{~m} \mathrm{PBS}$. After extensive washes in $0.1 \mathrm{~m}$ PBS, sections were exposed to an appropriate secondary (anti-rabbit or antimouse IgG) antibody conjugated to either Alexa-488 or Alexa-647 (Molecular Probes) for $30 \mathrm{~min}$ at $23^{\circ} \mathrm{C}$. Sections were then placed onto electrostatically charged slides and mounted underneath coverslips with Vectashield (Vector Laboratories, Peterborough, UK). Sections were imaged with a Bio-Rad Radiance confocal microscope equipped with a 488 $\mathrm{nm}$ emitting argon laser and a $637 \mathrm{~nm}$ emitting red diode enabling simultaneous acquisition of double fluorescently labeled sections.

Classification of interneurons. In a specific set of experiments, $0.5 \%$ biocytin was included in the intracellular solution during whole-cell recording from interneurons in $200 \mu \mathrm{m}$ coronal sections of hippocampus. In some cases, interneurons were actively filled with biocytin by current injection for up to $20 \mathrm{~min}(+200 \mathrm{pA}$ for $1 \mathrm{sec}$ at $0.5 \mathrm{~Hz}$ ). After recording and biocytin filling, interneurons were "depatched" by applying small amounts of positive pressure while slowly withdrawing the pipette to minimize cell damage and leaking of biocytin. Sections were then returned to oxygenated buffer for $1-2 \mathrm{hr}$ to enable diffusion of biocytin to distant processes and then placed in fixative at $4^{\circ} \mathrm{C}$ overnight. The next day, sections were processed for immunoreactivity for the calciumbinding proteins calbindin or calretinin or for the astrocyte marker GFAP as described above for $30 \mu \mathrm{m}$ fixed sections. After thorough washes in $0.1 \mathrm{M}$ PBS, sections were incubated in a solution containing streptavidin-conjugated to Alexa-488 (dilution, 1:1000; Molecular Probes) as well as appropriate fluorescent secondary antibodies for visualization of calbindin, calretinin, or GFAP immunoreactivity as described above. Sections were placed on electrostatically charged slides and mounted underneath coverslips with Vectashield (Vector Laboratories). Sections were imaged with a Bio-Rad Radiance confocal microscope (see above). In many cases, we collected several image series going deep into the slice (Z-stacks) using a $100 \times$ oil immersion lens (Nikon, Tokyo, Japan). These images were later used to determine the shape and dendritic orientation of the biocytin-filled interneuron using Bio-Rad software, NIH ImageJ, and CorelDraw12 (Corel, Maidenhead, UK).

Chemicals. All chemicals used were from Tocris Cookson (Bristol, UK) or Sigma (Poole, UK). Fluorescent dyes were from Molecular Probes. The chemicals are pyridoxal-phosphate-6-azophenyl-2',4'-disulfonic acid (PPADS), CNQX, L-(+)-2-amino-5-phosphonopentanoic acid (LAP-5), 2-methylthio-ATP (2MeSATP), 2-methylthio-ADP (2MeSADP), adenosine 5'-o-(2-thiodiphosphate) (ADP $\beta S)$, RS-3,5-dihydroxyphenylglycine (DHPG), and 2-methyl-6-(phenylethynyl)pyridine hydrochloride (MPEP).

Analysis. Synaptic currents were analyzed using MiniAnalysis program 5.6.22 (Synaptosoft, Decatur, GA), Strathclyde Electrophysiology Software (John Dempster, University of Strathclyde, Glasgow, Scotland, UK), pCLAMP9 (Axon Instruments), Origin 6.1 (OriginLab, Northampton, MA), and Graphpad Instat 3.06 for Windows (GraphPad 
Software, San Diego, CA). Postsynaptic unitary IPSC (uIPSC) latency was defined as the time between the maximum slope of the presynaptic action potential rising phase and the initiation of the UIPSC (defined as a $5 \%$ deviation from baseline). Confocal and epifluorescence imaging data were analyzed using Image J, custom written macros for the MRC-600 and CorelDraw12. Data in the text and graphs are shown as mean \pm SEM from $n$ determinations as indicated. Two tailed $t$ tests were used for most statistical analyses with significance declared at $p<0.05$. The Kolmogorov-Smirnov two-sample test was used to compare cumulative probability curves of sIPSC amplitudes and mIPSC interevent intervals with significance declared at $p<0.05$.

\section{Results}

Unless otherwise stated, all of the experiments reported in this study are in the presence of the adenosine receptor antagonist $\operatorname{DPCPX}(10 \mu \mathrm{M})$, ruling out adenosine receptor involvement. We start by reporting the effects of exogenous ATP on single interneurons, astrocytes, and inhibitory transmission. We go on to study the effects of endogenous ATP on astrocyte signaling and synaptic inhibition in interneurons.

\section{ATP evokes slow inward currents and depolarizations of stratum radiatum interneurons}

S.r. interneurons were discriminated from CA1 pyramidal neurons with the aid of IR-DIC on the basis of anatomical location, characteristic somatic shape, and ability to fire high-frequency action potentials (see next section for interneuron classification). ATP, or the more stable analog ATP $\gamma \mathrm{S}$, failed to evoke inward currents when puffed briefly to voltage-clamped s.r. interneuron somata (Khakh et al., 2003) (100 $\mu \mathrm{M} ; 10-500 \mathrm{msec} ; 2.6 \pm 1.7 \mathrm{pA}$ change in holding current at $-60 \mathrm{mV} ; n=12$ ) (Fig. $1 A$ ). However, rapid bath application of ATP $\gamma \mathrm{S}$ (see Materials and Methods) evoked peak inward currents of $-36.0 \pm 6.7 \mathrm{pA}(20-80 \%$ rise time; $25.7 \pm 5.2 \mathrm{sec} ; n=24$ ) (Fig. $1 B$ ). These slow ATP $\gamma S$ evoked currents showed little desensitization for agonist applications of $180 \mathrm{sec}$, and slow-incomplete recovery such that the residual current remaining 5 min after washout was $36.6 \pm 3.1 \%$ of that at the peak $(n=24)$ (Fig. $1 C)$. In contrast to the results with ATP $\gamma \mathrm{S}$, glutamate readily evoked reversible inward currents whether it was puffed briefly onto the soma to activate AMPA channels (Fig. $1 B$ ) or applied to the bath when ionotropic glutamate receptors were blocked (Fig. 1C) $(-271.4 \pm 44.1 \mathrm{pA}$ for puff application, $n=12 ;-103.8 \pm 31.6 \mathrm{pA}$ for bath application, $n=8)$. These experiments suggest that, although glutamate activates receptors on interneuron somata, ATP may activate receptors accessible only when agonist was applied more globally and rapidly to the slice. Alternatively, or in addition, ATP $\gamma \mathrm{S}$ may activate receptors on nearby astrocytes to cause the release of ATP or other substances (Newman, 2003a) that then act on the interneurons to evoke the slow inward current (Fig. 1C). We address these possibilities below.

In current-clamp recordings, $\mathrm{ATP} \gamma \mathrm{S}$ caused a significant $(+10.7 \pm 0.4 \mathrm{mV})$ depolarization of interneurons from resting levels $(-65.2 \pm 1.5 \mathrm{mV} ; n=10)$ (Fig. $1 D)$. In 8 of 10 neurons, the depolarization was sufficient to cause interneurons to fire action potentials (Fig. $1 D$ ). The size of the ATP $\gamma S$-evoked depolarization was of similar magnitude when action potentials were blocked $(+10.4 \pm 0.6 \mathrm{mV}$ in the presence of TTX; $n=7 ; p>$ 0.05 ) (Fig. $1 E$ ). In the other two (of 10) cases, where the depolarization was small $(<5 \mathrm{mV})$, ATP $\gamma \mathrm{S}$ increased the excitability of interneurons such that the interneurons fired more action potentials at lower levels of depolarizing current (Fig. $1 F$ ). We also performed extracellular cell-attached recordings from interneurons at the more physiological temperature of $34^{\circ} \mathrm{C}$. All neurons
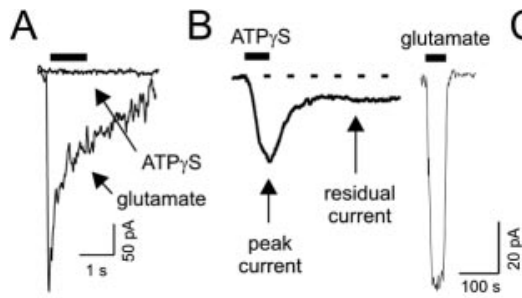

C

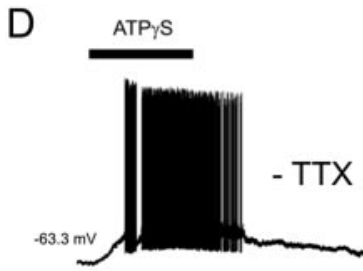

$E$
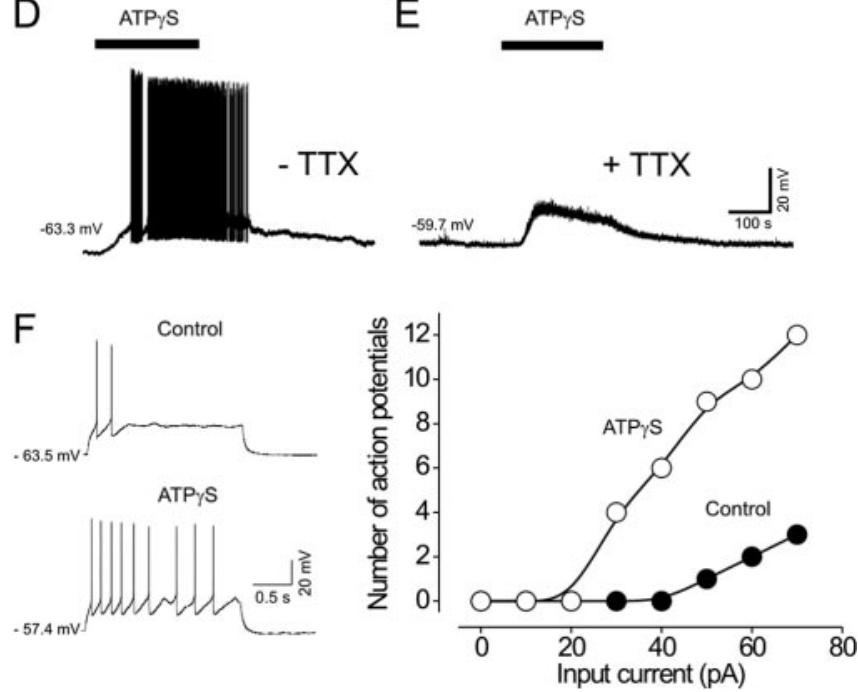

Figure 1. Slow ATP $\gamma S$ evoked excitation of interneurons. $A$, Stratum radiatum interneurons were held in voltage clamp $(-60 \mathrm{mV})$, and ATP $\gamma \mathrm{S}(100 \mu \mathrm{m})$ and glutamate $(10 \mu \mathrm{m})$ were puffed for 500 msec to the neuron cell body. These recordings were made in aCSF not containing CNQX. B, Bath application of the same concentrations of ATP $\gamma S$ and glutamate in the presence of CNQX (10 $\mu \mathrm{m})$. C, Normalized ATP $\gamma S$ and glutamate evoked peak currents shown in $B$. Note the differences in rise and decay times. D, S.r. interneurons depolarized and generated action potentials during bath application of $100 \mu \mathrm{M}$ ATP $\gamma$ S. E, The action potentials were blocked by 1 $\mu M$ TTX revealing the underlying ATP $\gamma S$-evoked depolarization. F, Example traces from an s.r. interneuron held in current clamp with $50 \mathrm{pA}$ of depolarizing current injection before (top trace) and in the presence of ATP $\gamma S$ (bottom trace). The graph on the right shows the number of action potentials generated during each depolarizing current step under control conditions and in the presence of $100 \mu \mathrm{m}$ ATP $\gamma \mathrm{S}$.

that responded to glutamate with an increase in action potential firing $(14.7 \pm 3.8 \mathrm{~Hz})$ responded likewise to ATP $\gamma \mathrm{S}(62.9 \pm 9.9$ $\mathrm{Hz} ; n=9)$. Collectively, these experiments indicate that although the slow response to ATP $\gamma \mathrm{S}$ is modest under voltage-clamp conditions (Fig. $1 B$ ), it is of sufficient size to excite interneurons.

\section{ATP excites calbindin- and calretinin-positive stratum radiatum interneurons}

All interneurons in s.r.-s.l-m. responded to ATP with responses similar to those described above (266 interneurons from 180 mice over a 1 year period) (Fig. 1). We next sought to further classify these interneurons within the framework proposed on the basis of morphological, biochemical, and electrophysiological properties (Parra et al., 1998). We started by performing an initial survey of calcium-binding protein expression (parvalbumin, calretinin, or calbindin) in $30 \mu \mathrm{m}$ sections of juvenile mouse hippocampus (Fig. 2A). Consistent with recent mouse studies (Matyas et al., 2004), interneurons within s.r.-s.l-m. were predominantly calbindin and calretinin immunoreactive, whereas parvalbumin immunoreactivity was limited to stratum oriens (s.o.) and s.r. areas close to the pyramidal cell layer (Fig. $2 \mathrm{~A}$ ). We consider it unlikely that the electrophysiological responses described in this study (Fig. 1) are from parvalbumin-expressing 
A
Parvalbumin

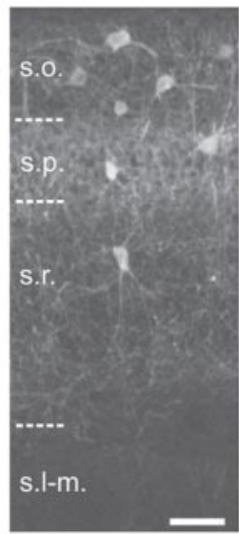

B

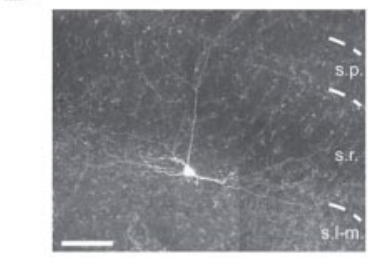

C

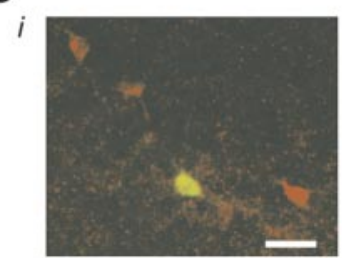

iii

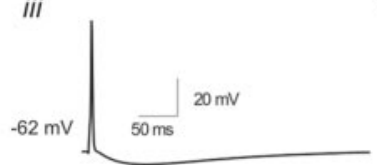

Calbindin
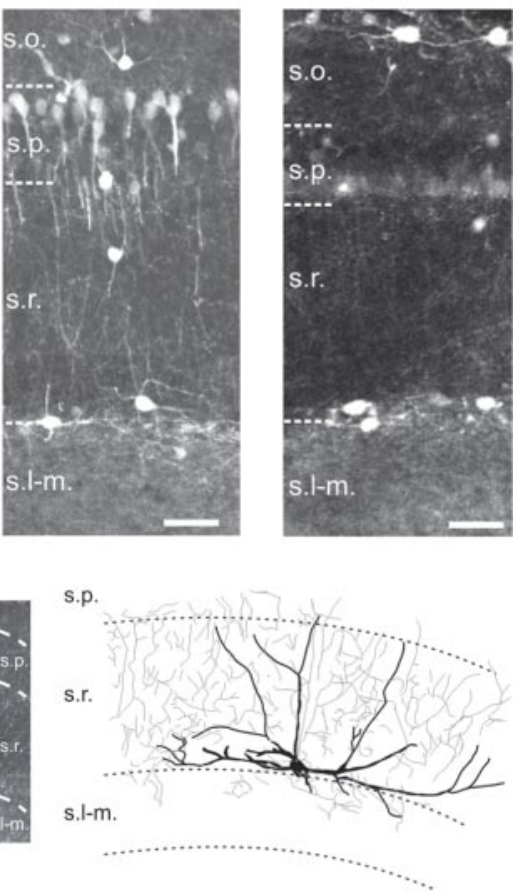

ii

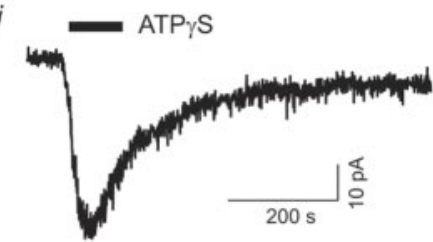

iv

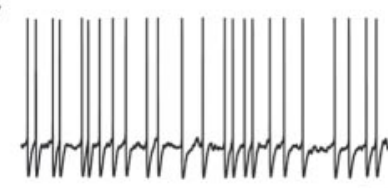

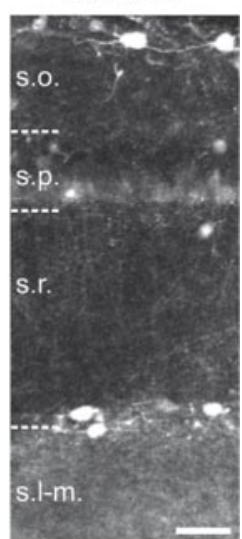

.

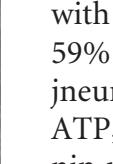

\section{jo} ATP, $\sim 60-70 \%$ are calbindin positive and $\sim 30-40 \%$ are calretinin positive. Within these classes, defined by expression of the calcium-binding proteins calbindin and calretinin, ATP-evoked currents occurred in all neurons regardless of soma location, dendritic orientation, firing pattern, resting membrane potential, or action potential half width (supplemental material, available at www.jneurosci.org) (Fig. 2). The basic properties of interneurons reported in this study are consistent with past work (Parra et al., 1998; Matyas et al., 2004).

The slow ATP-evoked response increases synaptic inhibition If interneurons fire more readily in response to ATP (Fig. $1 F$ ), then does this have an impact on their postsynaptic targets within the hippocampal circuit? To address this, we determined whether ATP $\gamma S$ could increase GABAergic synaptic events onto s.r.-s.l-m. interneurons and CA1 pyramidal neurons. Interneurons were voltage clamped with a $\mathrm{KCl}$-based intracellular solution $\left(E_{\mathrm{Cl}}=\right.$ $-1.3 \mathrm{mV}$ ) to allow the detection of inward $\mathrm{GABA}_{\mathrm{A}}$ receptormediated IPSCs at $-60 \mathrm{mV}$ (Fig. $3 A$ ). In 21 of 26 neurons, application of ATP $\gamma \mathrm{S}(100 \mu \mathrm{M})$ evoked an inward current $(-28.9 \pm$ $4.2 \mathrm{pA})$ and an increase in both the frequency ( $2.7 \pm 0.5$ to $9.6 \pm$ $2.0 \mathrm{~Hz}$ ) and amplitude of spontaneous IPSCs (sIPSCs; in all cases, the amplitude distributions shifted to larger peaks) (Fig. $3 B$ ). The sIPSCs evoked by ATP $\gamma \mathrm{S}$ were blocked by bicuculline and TTX (data not shown). These experiments suggest that when s.r.s.l-m. interneurons are excited by ATP $\gamma \mathrm{S}$, they fire action potentials and release GABA onto their postsynaptic targets, thus increasing inhibition within the network. To further explore this possibility, we recorded from connected pairs of s.r.-s.l-m. interneurons (Fig. 3C). The probability of a single evoked action potential causing a uIPSC $(-75.5 \pm 11.0 \mathrm{pA})$ in the postsynaptic interneuron was $0.24 \pm 0.04$ ( $n=14$ pairs; 100 trials per pair). ATP $\gamma \mathrm{S}$-evoked spontaneous action potential firing in eight of nine presynaptic interneurons and 28\% (probability, $0.28 \pm 0.09$; $n=8$ ) of these triggered uIPSCs in the postsynaptic interneurons (Fig. 3C) $(-75.5 \pm 11.4 \mathrm{pA})$.

We next tested whether the s.r. interneurons that are excited by ATP $\gamma S$ synapse exclusively onto other interneurons or additionally onto output CA1 pyramidal cells. Bath-applied ATP $\gamma S$ failed to evoke inward currents in CA1 pyramidal neurons (Khakh et al., 2003) (Fig. 3D) $(n=8)$ but dramatically increased the frequency and amplitude of sIPSCs in a TTX-sensitive manner (seven of eight neurons) (Fig. 3E). We recorded from connected pairs of SR interneurons and CA1 pyramidal neurons to determine whether the ATP $\gamma S$-evoked increase in sIPSC frequency onto pyramidal neurons (Fig. $3 F$ ) arises from s.r. or other interneurons within the slice. The probability of a spontaneous action potential causing a UIPSC in the postsynaptic pyramidal neuron was $0.57 \pm 0.01$, and in the presence of ATP $\gamma \mathrm{S}$, this was $0.60 \pm 0.02$. However, uIPSCs triggered by presynaptic ATP $\gamma S$ evoked action potentials were larger than those evoked by action potentials as a result of depolarizing current injection into the presynaptic neurons $(-81.4 \pm 7.0 \mathrm{pA}$ vs $-55.1 \pm 4.7 \mathrm{pA} ; p<$ 
$0.05)$; the $\mathrm{GABA}_{\mathrm{A}}$ synaptic conductance was increased from $0.9 \pm 0.1$ to $1.4 \pm 0.1$ $\mathrm{nS}(n=8)$. Thus, ATP $\gamma \mathrm{S}$ increased inhibition onto output pyramidal neurons in two ways, by increasing the frequency of IPSCs and by triggering IPSCs of larger synaptic conductance. The increased synaptic conductance may be caused by presynaptic effects of ATP such as facilitation or to postsynaptic effects, which may have increased $\mathrm{GABA}_{\mathrm{A}}$ receptor-mediated responses in pyramidal neurons. We hope to discriminate between these two possibilities in future experimental work. Together, our data from interneuron-interneuron and interneuron-pyramidal neuron pairs suggest that although the effect of ATP on single interneurons is excitatory (Fig. 1), its effect at the level of the network is dominated by heightened synaptic inhibition (Fig. 3).

\section{A role for $\mathrm{P} 2 \mathrm{Y}_{1}$ receptors}

The ATP $\gamma \mathrm{S}$-evoked inward current in interneurons developed slowly with a $20-$ $80 \%$ rise time of $25.7 \pm 5.2 \mathrm{sec}$ (Fig. $1 C$ ). Moreover, membrane conductance was unaltered $(1.6 \pm 0.2 \mathrm{nS}$ in control to $1.6 \pm$ $0.2 \mathrm{nS}$ in ATP $\gamma S ; n=23$ ) during the slow inward currents, whereas $\mathrm{P} 2 \mathrm{X}$ channels increase neuronal membrane conductance (North, 2002). The lack of effect on membrane conductance combined with strong membrane potential depolarization (Fig. 1) recalls similar data with muscarinic agonists and suggested the activation of metabotropic receptors (Shen and North, 1992; McQuiston and Madison, 1999). To

determine the nature of the receptors responsible for the responses described in Figures 1-6, we exploited the known pharmacological properties of ATP receptors. We used two measures of receptor activation, the amplitude of the agonist-evoked inward current in single neurons and percentage of increases in the frequency of sIPSCs onto single SR interneurons. We began by examining the relative effects of agonists known to activate distinct types of ATP receptors. Each putative agonist was applied for $3 \mathrm{~min}$, washed out for $7 \mathrm{~min}$, and then $100 \mu \mathrm{M}$ ATP $\gamma \mathrm{S}$ was applied to verify that the interneuron was responsive to this control agonist. Inward currents similar to those evoked by ATP $\gamma \mathrm{S}$ were observed for ATP (1 mM; pH 7.4), 2MeSATP (100 $\mu \mathrm{M})$, 2MeSADP $(100 \mu \mathrm{M})$, and ADP $\beta S(100 \mu \mathrm{M})$. In contrast, UTP (1 $\mathrm{mM}$; pH 7.4), $\alpha \beta$ meATP $(100 \mu \mathrm{M})$, and adenosine ( $1 \mathrm{mM}$ in the absence of DPCPX) were without effect (Fig. 4A,B). Overall, this agonist profile argues against $\mathrm{P} 1$ and $\mathrm{P} 2 \mathrm{X}$ receptors and implies the involvement of $\mathrm{P} 2 \mathrm{Y}_{1}, \mathrm{P}_{2} \mathrm{Y}_{11}$, or $\mathrm{P} 2 \mathrm{Y}_{12}$ receptors (von Kugelgen and Wetter, 2000). Consistent with this, the responses were blocked by the P2 receptor antagonist PPADS $(30 \mu \mathrm{M})$ and the $\mathrm{P}_{2} \mathrm{Y}_{1}$ antagonist $2^{\prime}$-deoxy-N 6-methyladenosine $\quad 3^{\prime}, 5^{\prime}$ bisphosphate (MRS2179; $10 \mu \mathrm{M}$ ) (Moro et al., 1998). A similar pharmacological profile was found when we measured the increase in sIPSCs arriving onto interneurons, which probably provides a better measure of increased synaptic inhibition across the network (Fig. 4C,D).
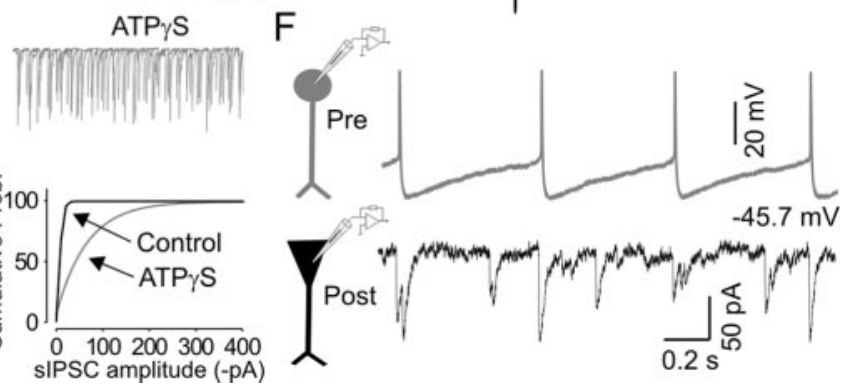

$\mathrm{F}$

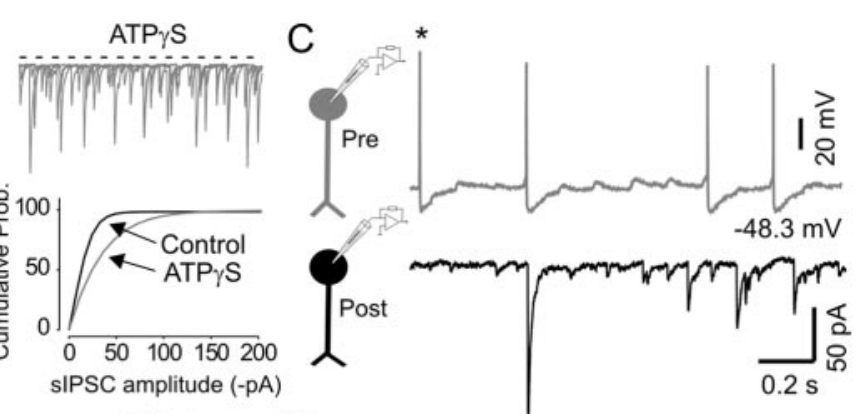

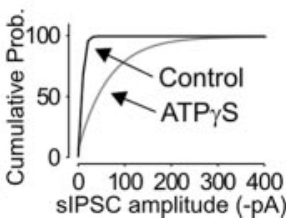

sIPSC amplitude (-pA) ans.

Figure 3. ATP increases synaptic inhibition onto stratum radiatum interneurons and CA1 pyramidal neurons. A, ATP $\gamma S$ caused an inward current as well an increase in the frequency (freq.) and amplitude of spontaneous IPSC $\operatorname{in} 21$ of 26 interneurons (traces ow 3 superimposed 3 sec sweeps). B, Left graph, Average data for changes in sIPSC frequency in the absence of TTX. Right graph, Top panel, Membrane potential recording from a presynaptic s.r. interneuron showing spontaneous action potentials during the caused no inard current but increased in the fromency and amplitude of sIPSCS in CA1 Pyramidal neurons (traces show rise times of $1.7 \pm 0.1 \mathrm{msec}$ and decay time constants of $13.4 \pm 0.7 \mathrm{msec}$, respectively ( $n=14$ pairs). $E$, Left graph, Average data In and CA1 pyramidal neuron as the postsynaptic cell held in voltage clamp. Top panel, Membrane potential recording from presynaptic s.r. interneuron showing spontaneous action potentials during the application of ATP $\gamma$ S. Bottom panel, Membrane $20-80 \%$ rise times of $1.0 \pm 0.2 \mathrm{msec}$ and decay time constants of $11.6 \pm 1.1 \mathrm{msec}(n=8$ pairs). s.r. - s.p. pairs had an average uIPSC latency of $4.1 \pm 0.3$ msec in control conditions and $4.2 \pm 0.3$ msec in ATP $\gamma S$ ( $n=5$ pairs; Fig. $3 g$ ).

We detected $\mathrm{P}_{2} \mathrm{Y}_{1}$ immunoreactivity in numerous CA1 interneurons in s.o., s.r., and s.l-m. (Fig. 4E), which was similar to the pattern observed for parvalbumin, calbindin, and calretinin expressing neurons (Fig. $2 A$ ). No $\mathrm{P}_{2} \mathrm{Y}_{1}$ staining was observed in CA1 pyramidal neurons, which is consistent with the lack of ATP-evoked currents in these cells (Khakh et al., 2003) (Fig. 3D). Higher magnification views clearly showed that the somata of interneurons in s.r. and s.l-m. are immunopositive for $\mathrm{P}_{2} \mathrm{Y}_{1}$ (Fig. $4 E$ ). Interestingly, within the s.r., there were numerous finer structures that were also immunopositive for $\mathrm{P}_{2} \mathrm{Y}_{1}$ receptors (Fig. $4 E$, arrows); these may represent the processes of interneurons and/or astrocytes. Overall, these pharmacological and antibody labeling experiments provide evidence for functional $\mathrm{P} 2 \mathrm{Y}_{1}$ receptors on interneurons (Moore et al., 2000; Moran-Jimenez and Matute, 2000).

\section{The peak and residual ATP-evoked inward currents are carried by two types of conductance}

We used the more specific agonist $A D P \beta S$ to gain insight into the ionic basis of the $\mathrm{P} 2 \mathrm{Y}_{1}$ receptor-mediated inward current (Fig. $4 B$ ) and either applied slow voltage ramps from -100 to $+40 \mathrm{mV}$ (over $15 \mathrm{sec}$ ) or $10 \mathrm{mV}$ voltage steps over the same voltage range before ADP $\beta S$ (Fig. 5Ai) at the peak of the inward current (Fig. $5 A$ ii) and after $A D P \beta S$ washout for $10 \mathrm{~min}$ at the residual phase of the current (Fig. 5Aiii,Biii). All data shown in Figure 5 are from 

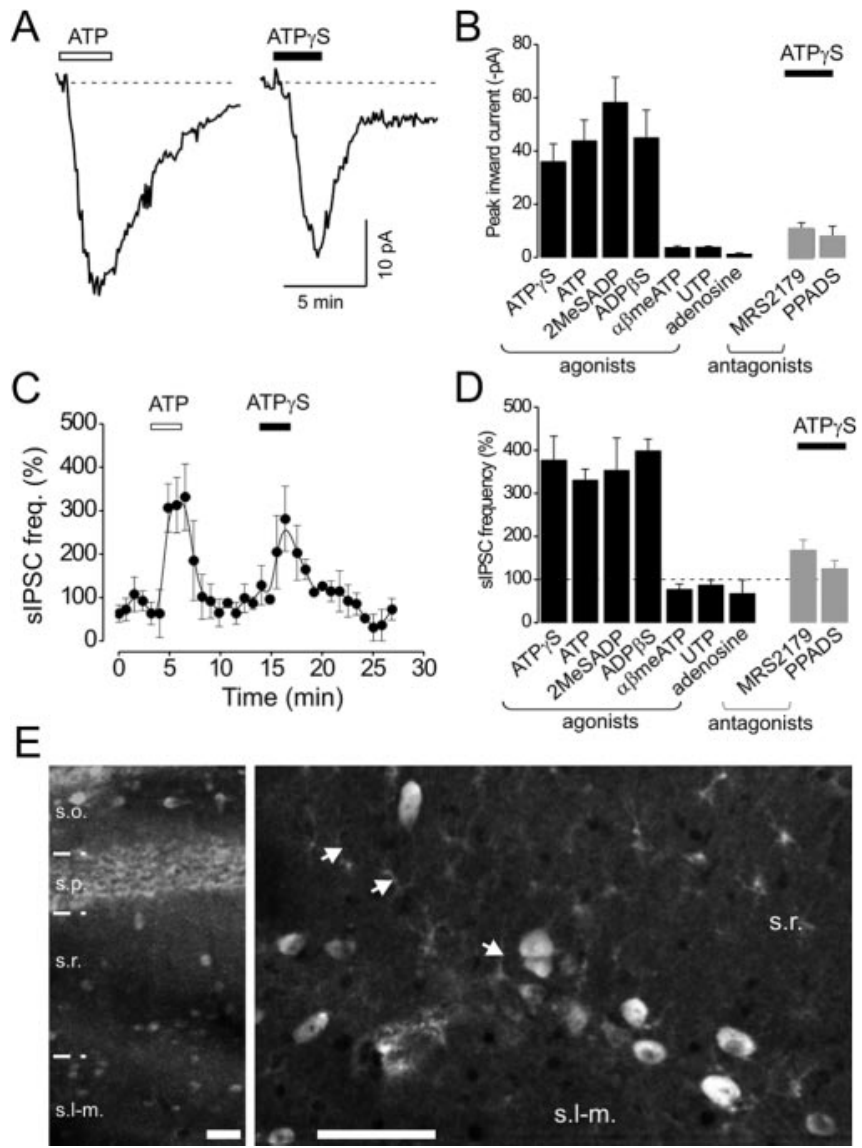

Figure 4. Pharmacological properties of ATP responses in SR interneurons. A, Exemplar traces showing whole-cell voltage-clamp currents at $-60 \mathrm{mV}$ first to a test nucleotide (ATP) and then to ATP $\gamma S(100 \mu \mathrm{M})$. B, Average data for each test agonist: ATP $\gamma S(100 \mu \mathrm{m} ; n=22)$, $\operatorname{ATP}(1 \mathrm{~mm} ;$ pH $7.4 ; n=8), 2 \mathrm{MeSADP}(100 \mu \mathrm{m} ; n=8), \operatorname{ADP} \beta S(100 \mu \mathrm{m} ; n=16), \alpha \beta$ meATP $(100 \mu \mathrm{m} ; n=10), \operatorname{UTP}(100 \mu \mathrm{m} ; n=11)$, and adenosine $(100 \mu \mathrm{m} ; n=7)$. Data are also shown for ATP $\gamma S$-evoked currents in slices incubated in MRS2179 (30 $\mu \mathrm{m} ; n=19)$ and PPADS (10 $\mu \mathrm{m}$; $n=6$ ). C, Spontaneous IPSCs were recorded in voltage-clamp mode at $-60 \mathrm{mV}$ (KCl intracellular solution) first to a test nucleotide agonist and then to test ATP $\gamma$ S. An example experiment is shown in (where the frequency of SIPSCs is normalized to baseline. D shows the average peak SIPSC frequency increase for each agonist tested: ATP $\gamma S(100 \mu \mathrm{m} ; n=21)$, ATP (1 mм; pH 7.4; $n=5), 2 \operatorname{MeSADP}(100 \mu \mathrm{m} ; n=7), \operatorname{ADP} \beta S(100 \mu \mathrm{m} ; n=16), \alpha \beta \operatorname{meATP}(100 \mu \mathrm{m} ; n=8)$, $\operatorname{UTP}(100 \mu \mathrm{m} ; n=11)$, and adenosine $(100 \mu \mathrm{m} ; n=6)$. Data are also shown for ATP $\gamma$ S-induced responses in slices incubated in MRS2179 (30 $\mu \mathrm{m} ; n=9)$ and PPADS $(10 \mu \mathrm{m} ; n=11)$. The

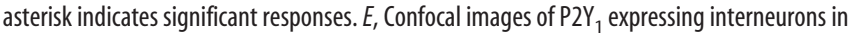
CA1. Scale bar, $50 \mu \mathrm{m}$. Note the highly fluorescent distinct somata are confined to interneurons in s.r., s.l-m., and s.o. The more diffuse staining in the pyramidal cell layer is probably not specific and has been observed by others (Matyas et al., 2004).

voltage ramps, but Table 1 includes average data for ramps and steps. The current-voltage relationship at the peak of the ADP $\beta S$ evoked inward current (ii minus $i$ ) was complex, with no apparent reversal potential over the range -100 to $+40 \mathrm{mV}$ (Fig. $5 C$ ), suggesting that the peak response may consist of at least two underlying currents with differing reversal potentials but overlapping activation ranges (Shen and North, 1992; McQuiston and Madison, 1999). We calculated the current-voltage relationship of the slow plateau current (Fig. 5D, iii minus $i$ ) and found the reversal potential to be $-89.6 \pm 1.5 \mathrm{mV}(n=10)$ close to the Nernst potential for $\mathrm{K}^{+}$ions at $-99.8 \mathrm{mV}$. This reversal potential is hard to see from the average graph (Fig. $5 D$ ), because the current was small and the reversal potentials varied between cells. To ameliorate this, we plotted the ramp current-voltage relationships for all neurons on an expanded scale (Fig. $5 D$, inset); it is

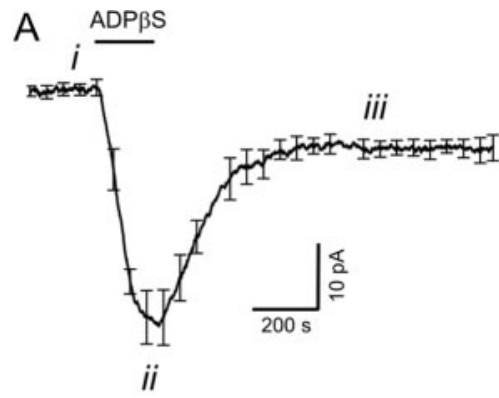

B
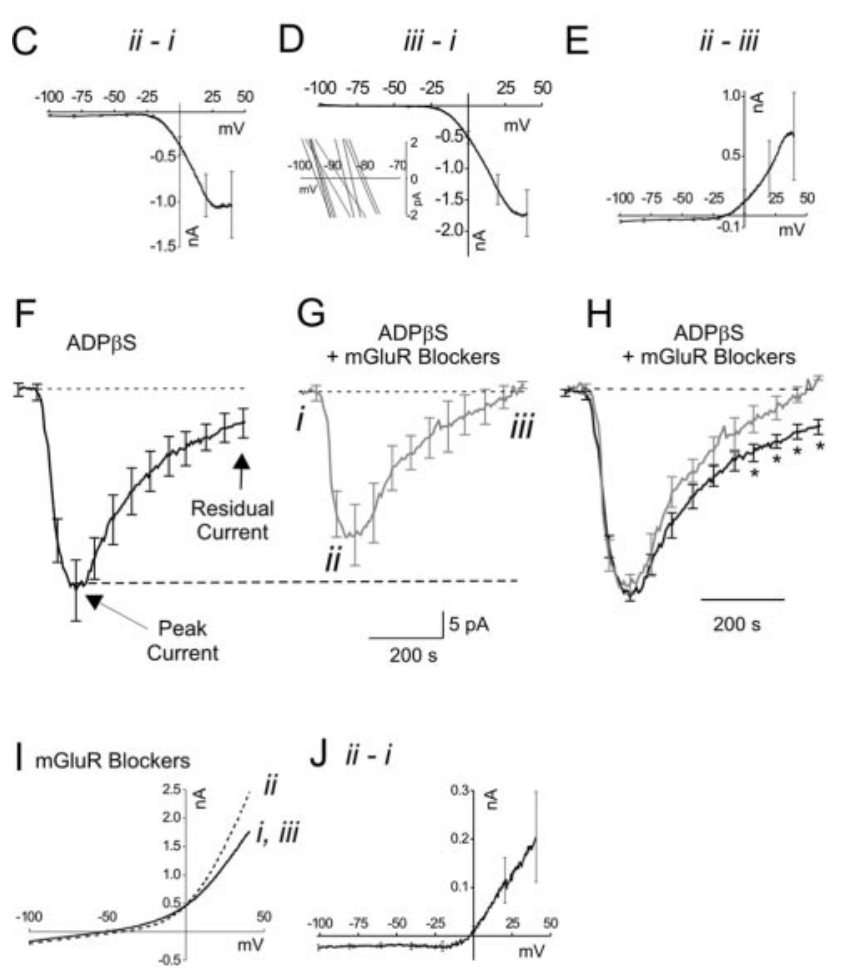

Figure 5. Electrophysiological properties of $\mathrm{P} 2 \mathrm{Y}_{1}$ receptor-mediated inward currents. $A$, The trace shows average ADP $\beta S$-evoked inward currents recorded from interneurons at $-60 \mathrm{mV}$ $(n=12)$. The points $i$,ii, and iii indicate the time when current-voltage relationships presented in $B-E$ were determined. Current-voltage $(I-V)$ relationships were determined using voltage ramps from -100 to $+40 \mathrm{mV}(9.3 \mathrm{mV} / \mathrm{sec})$ before $(i)$, at the peak of the ATP $\gamma$ S current $(i i)$, and after washout of ATP $\gamma S$ (iii) as indicated in $A$. The resulting $/-V$ relationships for a single experiment are shown in $B$. Subtraction of $/-V$ relationships indicates the average $I-V$ relationships of the peak and residual currents $(n=10 ;(-E)$. Inset in $D$ is an expanded $I-V$ region from -100 to $-80 \mathrm{mV}$ to show reversal potentials for each individual neuron. $F$, Average ADP $\beta S$-evoked currents recorded from interneurons under control conditions $(F)$ and then in the presence of group I mGluR antagonists MPEP and LY367385 (100 $\mu \mathrm{m} ; G)$. The points $i$, ii, and iii in $G$ indicate where current-voltage relationships presented in / and / were determined. $H$, Normalized traces shown in $F$ and $G$. I, Current-voltage relationships from ramps for an ADP $\beta S$-evoked current in the presence of mGluR blockers. J, Subtraction of $/-V$ relationships at $i$ and $i i$ i indicates the average $/-V$ relationship of the peak current, with reversal of the current close to $0 \mathrm{mV}(n=8)$.

clear that all of the currents do indeed reverse polarity, and the average data are presented in Table 1 . This suggests that the ATP $\gamma \mathrm{S}$-evoked residual current was attributable to suppression of a $\mathrm{K}^{+}$conductance (McQuiston and Madison, 1999). We determined the current-voltage relationship of the peak current (Fig. 5E, ii minus iii). The most salient features were as follows: (1) an inward current at $-60 \mathrm{mV}$, (2) little change in slope conductance in the range of -100 to $-20 \mathrm{mV}$, (3) strong outward rectification, and (4) a reversal potential $(-14.5 \pm 3.4 \mathrm{mV})$, suggestive of a nonselective cationic current. Together, these electrophysiological properties argue against P2X channels (North, 
2002) and instead imply activation of a nonselective cationic current (average current-voltage relationships for 10 cells are presented in Fig. 5C-E). Consistent with this, addition of the broad-spectrum cation channel blockers $\mathrm{Cd}^{2+}(30 \mu \mathrm{M} ; n=8)$ and $\mathrm{La}^{3+}(10 \mu \mathrm{M} ; n=8)$ reduced the amplitude of the inward current by $63.7 \pm$ $4.4 \%(n=8)$ and $72.7 \pm 5.4 \%(n=8)$, respectively. Interestingly, intracellular dialysis of interneurons with GDP $\beta$ S (100 $\mu \mathrm{M} ; n=6$ ) through the patch pipette to block G-protein-mediated signaling did not reduce the ATP $\gamma$ S-evoked inward current $(-30.3 \pm 3.2 \mathrm{pA}$ vs $-36.0 \pm 6.7 \mathrm{pA})$. This suggests that G-proteins are not involved, and $\mathrm{P}_{2} \mathrm{Y}_{1}$ receptors may directly couple to ion channels, as predicted from detailed heterologous expression studies (O'Grady et al., 1996; von Kugelgen and Wetter, 2000; Lee et al., 2003). Overall, the experiments presented in Figure 5 and Table 1 suggest that ADP $\beta$ S activation of $\mathrm{P}_{2} \mathrm{Y}_{1}$ receptors depolarizes interneurons by activating a nonselective cationic conductance and suppressing a $\mathrm{K}^{+}$conductance.

\section{The residual component of the ADP $\beta S$-evoked current was mediated by glutamate and accompanied by persistent increases in astrocyte $\mathrm{Ca}^{2+}$ oscillations}

We considered the possibility that a component of the ATPevoked responses recorded from interneurons may be secondary to astrocyte activation and the release of glutamate (Parpura and Haydon, 2000; Newman, 2003b; Liu et al., 2004). The responses described in this study are not caused by kainate-AMPA-NMDA channels because they were not affected by CNQX and AP-5 (10 $\mu \mathrm{M})$. We explored the possibility that metabotropic glutamate receptors (mGluRs) may contribute to part of the ATP $\gamma \mathrm{S}$-evoked inward current (Figs. $1 B, 5 A$ ), because group I mGluRs are expressed in hippocampal interneurons (van Hooft et al., 2000) and astrocytes are known to release glutamate in response to elevated $\mathrm{Ca}^{2+}$ levels (Pasti et al., 2001). Consistent with previous work (Mannaioni et al., 2001), bath application of the group I mGluR agonist DHPG $(10 \mu \mathrm{M})$ activated inward currents in interneurons $(-46.6 \pm 7.9 \mathrm{pA} ; n=7)$ that could be blocked with mGluR antagonists MPEP and $(S)-(+)$ - $\alpha$-amino-4-carboxy-2methylbenzeneacetic acid (LY367385) (100 $\mu \mathrm{M}$; antagonists of $\mathrm{mGluR}_{5}$ and $\mathrm{mGluR}_{1 \mathrm{a}}$ receptors, respectively). This current, like the residual ADP $\beta S$-evoked current (Fig. 5D), is caused by suppression of a K ${ }^{+}$conductance (Krause et al., 2002). The mGluR blockers also reduced the peak ADP $\beta$ S-evoked current by $\sim 20 \%$ in all cases, although this did not reach significance $(n=12)$ (Fig. $5 F, G)$. However, the ADP $\beta S$-evoked residual current was abolished when metabotropic glutamate receptors were blocked (Fig. $5 G, H)$. This is further evidenced by voltage-ramp experiments (Fig. 5I). With mGluR blocked the peak current-voltage relationship shows a reversal potential $(-3.2 \pm 1.0 \mathrm{mV} ; n=8)$ indicative of a nonselective cationic current and a shape almost identical to that calculated for the peak current by subtraction (Fig. 5, compare $E$ and $J$ ). In short, when mGluRs were blocked, the ADP $\beta S$-evoked inward current displayed no residual component, and there was no evidence for suppression of a $\mathrm{K}^{+}$conductance by $\mathrm{ADP} \beta \mathrm{S}$. We suggest the residual current (Figs. $1 B, 5 A$ ), which is dominated by suppression of a $\mathrm{K}^{+}$conductance (Fig. $5 D)$ and persists even when the agonist has been washed from the slice (Figs. $1 B, 5 A$ ), is primarily attributable to $\mathrm{ADP} \beta S$-evoked glutamate release acting on group I metabotropic glutamate receptors (Krause et al., 2002). Because interneurons have dendritic arbors, we cannot rule out the possibility that the reported reversal potential estimates may be contaminated to some extent by unavoidably inadequate voltage clamp of distal processes. The data should be interpreted with these considerations in mind.

Astrocytes are potential sources of endogenous glutamate release in response to $\mathrm{P} 2 \mathrm{Y}$ receptor activation. But are astrocytes actually excited by $\mathrm{P} 2 \mathrm{Y}$ receptor agonists in our experiments in brain slices? To address this, we applied ATP $\gamma S$ or ADP $\beta S$ (100 $\mu \mathrm{M}$ ) (Fig. $6 \mathrm{~B}$ ), monitored interneuron transmembrane current, and imaged $\mathrm{Ca}^{2+}$ levels in astrocytes in the s.r.-s.l-m. (Fig. $6 A-C$ ) (movie in supplemental material, available at www. jneurosci.org). Some astrocytes displayed spontaneous $\mathrm{Ca}^{2+}$ oscillations, whereas others fluoresced only in ADP $\beta S$, confirming that functional P2Y receptors are expressed in astrocytes (Fam et al., 2000; Koizumi et al., 2003). On average, the ADP $\beta S$-evoked increase in astrocyte $\mathrm{Ca}^{2+}$ levels displayed rise times of $11.3 \pm 1.8 \mathrm{sec}$, whereas the peak current recorded concomitantly from interneurons was slower $(61.5 \pm 3.7 \mathrm{sec})$ (Fig. $6 C)$. Thus, at the peak of the astrocyte $\mathrm{Ca}^{2+}$ increase, the inward current had developed by only $31.2 \pm 4.7 \%$, whereas at the time of the peak current, the astrocyte $\mathrm{Ca}^{2+}$ level had already decayed by $54.1 \pm 6.5 \%(n=33)$. Moreover, there was no correlation between the magnitude of the peak ADP $\beta$ Sevoked current and the peak $\Delta F / F$ in astrocytes $(r=0.4)$, implying that the two responses were independent. How then do $\mathrm{P}_{2} \mathrm{Y}_{1}$ receptor agonists cause release of glutamate that mediates the residual current (Fig. 5H) recorded from interneurons? Interestingly, we observed persistent increases in the number of $\mathrm{Ca}^{2+}$ oscillations within astrocytes when the $\mathrm{P} 2 \mathrm{Y}_{1}$ receptor agonists had been washed from the bath. This is evident in astrocytes $1,3,4$, and 5 in Figure $6 B$, and two other examples are shown on an expanded scale in Figure $6 D$ before and $5 \mathrm{~min}$ after ADP $\beta$ S. Quantification revealed that the vast majority of astrocytes (88\%) within the s.r.-s.l-m. showed increased $\mathrm{Ca}^{2+}$ oscillations (Fig. 6E), which was reflected as a significant increase in the coefficient of variation (SD divided by mean) in astrocyte $\mathrm{Ca}^{2+}$ levels (Fig. $6 \mathrm{~F}$ ). The oscillatory responses in astrocytes are not likely to be a secondary consequence of neuron activation, because the experiments were performed in the presence of TTX. We propose that the residual ATP $\gamma \mathrm{S}$-evoked current recorded from interneurons that persists even when ATP $\gamma \mathrm{S}$ has been removed is because of persistent increases in $\mathrm{Ca}^{2+}$ oscillations within astrocytes that release glutamate (Parpura and Haydon, 2000; Newman, 2003b) to activate metabotropic glutamate receptors on interneurons.

\section{Evidence for endogenous activation of $\mathrm{P} 2 \mathrm{Y}$ receptors on astrocytes}

Astrocytes can be activated by numerous stimuli as they functionally express receptors for the transmitters glutamate, acetyl- 

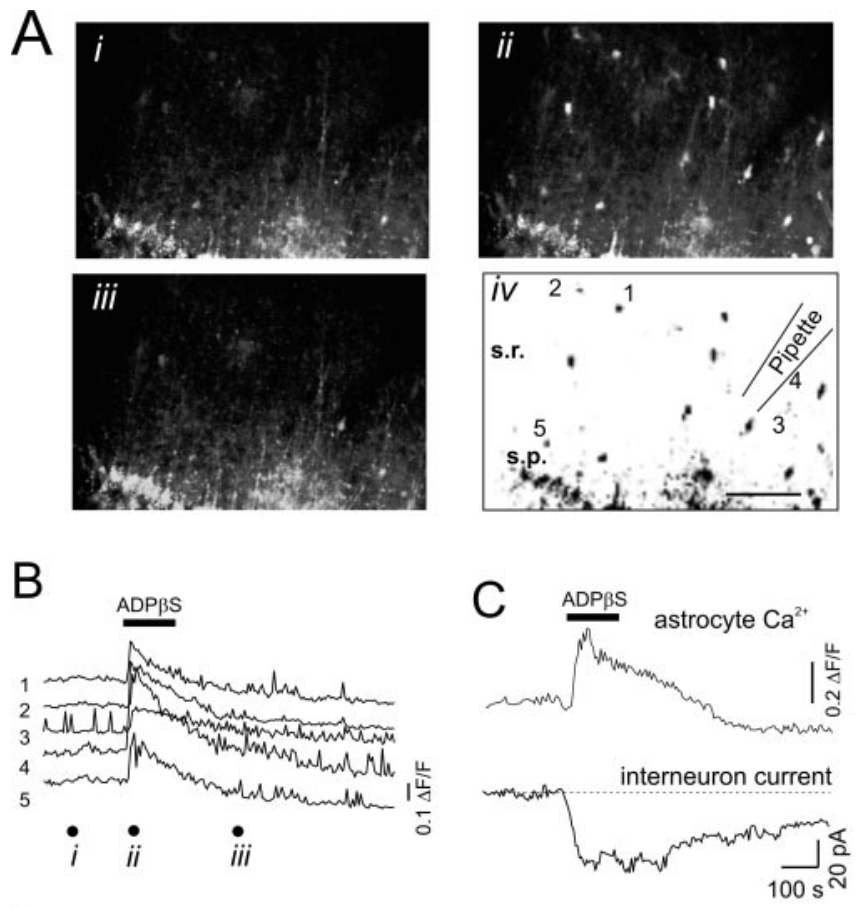

D Before ADP $\beta S$ After ADP $\beta$ S
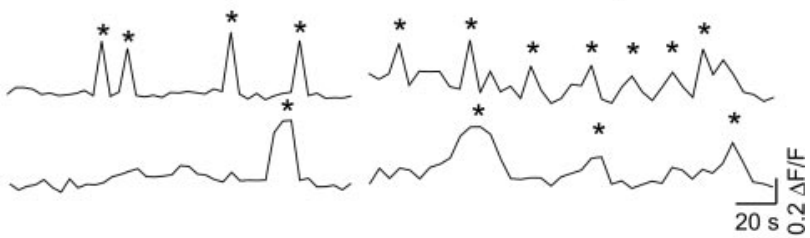

$E$

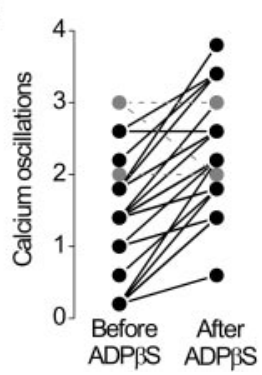

$\mathrm{F}$

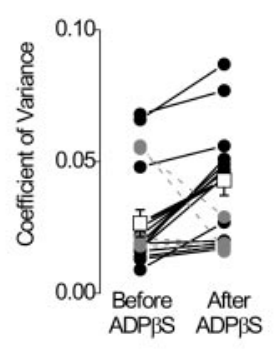

Figure 6. Astrocyte $\mathrm{Ca}^{2+}$ dynamics. A, Fluorescence micrographs of an acute hippocampal slice loaded with fluo-4-AM (see Materials and Methods) before (i), during (ii), and after (iii) $A D P \beta S$. iv indicates the location of the astrocytes that were monitored (numbered 1-5) and hippocampal cell layers as well as the location of the recording pipette (the patched interneuron was below the confocal section). Scale bar, $50 \mu \mathrm{m}$. B, Traces showing changes in intracellular $\mathrm{Ca}^{2+}$ for five representative astrocytes indicated in the panels in $A$. C, Average fluorescence trace from nine astrocytes and the corresponding interneuron current in this experiment. $D$, Traces showing spontaneous $\mathrm{Ca}^{2+}$ oscillations before and after ADP $\beta S$ for two astrocytes on an expanded time scale. The asterisk indicates a transient peak in intracellular $\mathrm{Ca}^{2+}$ concentration. $E$, Number of oscillations in the $200 \mathrm{sec}$ before and $200 \mathrm{sec}$ after ADP $\beta S$ for 33 astrocytes. $F$, Coefficient of variance was also measured before and after ADP $\beta S$ as a measure of astrocyte activity. In $F$, astrocytes with increased oscillations are shown in black, and those with decreased oscillations are shown in gray.

choline, noradrenaline, serotonin, and ATP (Haydon, 2001). In vitro electrical stimulation of Schaffer collateral (SC) afferents leads to excitation of astrocytes in the CA1 region (Porter and McCarthy, 1996). This effect has been partly attributed to glutamate release, which acts on metabotropic glutamate receptors of neighboring astrocytes. SC terminals have also been shown to release ATP (Wieraszko et al., 1989; Pankratov et al., 1998). We
A

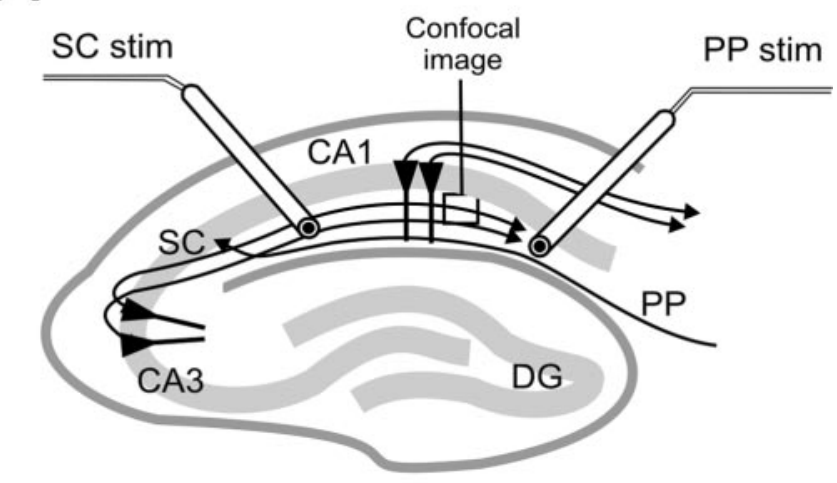

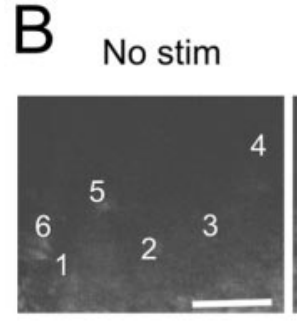

C

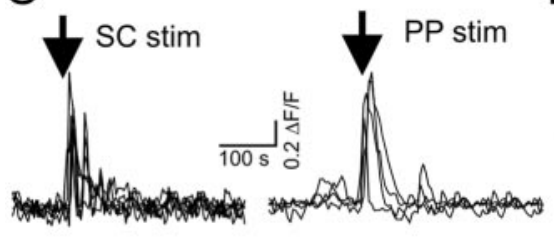

\section{Stim SC}

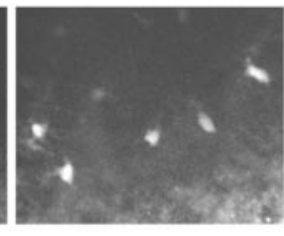

D

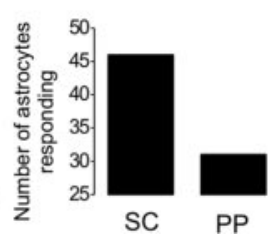

Figure 7. Astrocyte activation by stimulation (stim) of the Schaffer collaterals and the peforant path. $A$, Schematic diagram of the hippocampus showing glutamatergic SC and PP axons. A concentric wire electrode was placed in stratum radiatum to stimulate SC or PP axons as indicated, whereas $\mathrm{Ca}^{2+}$ transients were recorded in astrocytes. $B$, Fluorescence micrographs of fluo-4-loaded astrocytes in s.r. without stimuli, with SC stimuli, and with PP stimuli. Numbers in the left panel indicate astrocytes monitored to obtain recordings shown below in C. D, Bar graph indicating number of astrocytes that responded to SC and PP stimulation from eight slices.

thus explored the possibility that ATP may activate nearby astrocytes. We used similar conditions to those already reported for SC stimulation (Porter and McCarthy, 1996) but also stimulated the perforant path (PP) axons from entorhinal cortex and recorded calcium signals from $\mathrm{CA} 1$ astrocytes in the same s.r.-s.l-m. area (Fig. 7A). Astrocytic calcium responses were evoked by trains of stimuli $(300-800 \mu \mathrm{A} ; 30 \mathrm{~Hz} ; 3 \mathrm{sec})$ similar to those used by researchers to induce calcium responses and long-term synaptic potentiation in hippocampal pyramidal neurons (400-1000 $\mu \mathrm{A}$; $50 \mathrm{~Hz} ; 2 \mathrm{sec}$ ) (Regehr et al., 1989; Regehr and Tank, 1990) and calcium responses in astrocytes $(200-400 \mu \mathrm{A} ; 50 \mathrm{~Hz} ; 2 \mathrm{sec})$ (Porter and McCarthy, 1996). Stimulating electrodes were placed between $\sim 300$ and $\sim 750 \mu \mathrm{m}$ from the confocal imaging site in all eight slices examined. In five slices, we first stimulated the PP and then repositioned the electrode to stimulate the SC (Fig. 7A) (the order was reversed for three slices). As shown in the fluorescence micrographs (Fig. $7 B$ ) and the overlaid astrocyte $\mathrm{Ca}^{2+}$ transients (Fig. $7 C$ ), only a proportion of the cells activated by SC stimulation were also activated by PP stimulation (six and four astrocytes, respectively, for the exemplar experiment in Fig. 7C). This was true of all eight slices investigated $(73.8 \pm 12.5 \%$ of SC- 
stimulated astrocytes responded to $\mathrm{PP}$ stimulation). These differences suggest that excitation of astrocytes may be stronger for the SC as opposed to the PP pathway (Fig. $7 C, D$ ). We next determined whether local stimulation within s.r. could evoke similar responses in astrocytes. A glass monopolar electrode was positioned in the center of the confocal field of view, and astrocyte calcium was monitored while the length of the stimulation train was gradually increased from 1 to 80 stimuli $(10-40 \mu \mathrm{A} ; 30 \mathrm{~Hz}$ ) (Fig. $8 A, B)$. This experiment was repeated in six slices, and the results of two experiments are shown in Figure $8 B$. Astrocytes closest to the electrode were activated by lower numbers of stimuli than those further from the point of stimulation, for which activation was also delayed (Fig. 8 B) (also see below). All loaded astrocytes could be activated with 80 stimuli at $30 \mathrm{~Hz}$. We chose to use 100 stimuli at 30 $\mathrm{Hz}$ in subsequent pharmacological experiments to ensure reproducible astrocyte activation.

How does local electrical stimulation within s.r. cause astrocyte $\mathrm{Ca}^{2+}$ responses? Within a $\sim 200 \mu \mathrm{m}$ square field of view, $95 \%$ of the astrocyte responses (56 of 59 astrocytes; nine slices) were blocked by TTX ( $1 \mu \mathrm{M})$. Moreover, astrocyte responses were abolished (46 of 46 cells; six slices) when voltage-gated $\mathrm{Ca}^{2+}$ channels were blocked with cadmium (10 $\mu \mathrm{M})$ (Fig. $8 C, D$ ). Finally, very few astrocytes (Fig. $8 C$ ) responded during electrical stimulation in slices that had been preincubated in botulinum neurotoxin $\mathrm{E}$ to cleave synaptosomal-associated protein of 25 kDa (SNAP-25) (BoToxE, $20 \mu \mathrm{g} / \mathrm{ml}, 4 \mathrm{hr}$ ), constituting a blockade of the response by $>93 \%$ (Fig. 8C,D). Because (1) the majority of CA1 s.r. astrocytes do not express TTX-sensitive $\mathrm{Na}^{+}$channels (Sontheimer and Waxman, 1993), (2) there is no evidence to indicate that s.r. astrocytes express voltage-gated $\mathrm{Ca}^{2+}$ channels, and (3) astrocytes mostly express SNAP-23 rather than SNAP-25 (Sadoul et al., 1997; Wilhelm et al., 2004), these data imply that the trigger for astrocyte responses during electrical stimulation is exocytic release of transmitter from SC and/or $\mathrm{PP}$ nerve terminals. These experiments do not address the possibility that astrocytes may also release transmitter by exocytosis but rather support the hypothesis that the initiating stimulus for the responses described in Figure 8 is release from nerve terminals.

If astrocytes are activated through release from nerve terminals, then which transmitter is responsible? In a series of experiments, we applied trains of stimuli in the center of the field of view $(313$ by $208 \mu \mathrm{m})$ and imaged $\mathrm{Ca}^{2+}$ changes in s.r. astrocytes (Fig. 9) (movies in supplemental material, available at www. jneurosci.org). Under these conditions, astrocyte $\mathrm{Ca}^{2+}$ increases were measured in surrounding astrocytes (Fig. $8 A$ ) up to $\sim 200$ $\mu \mathrm{m}$ from the stimulating electrode. As alluded to earlier, the
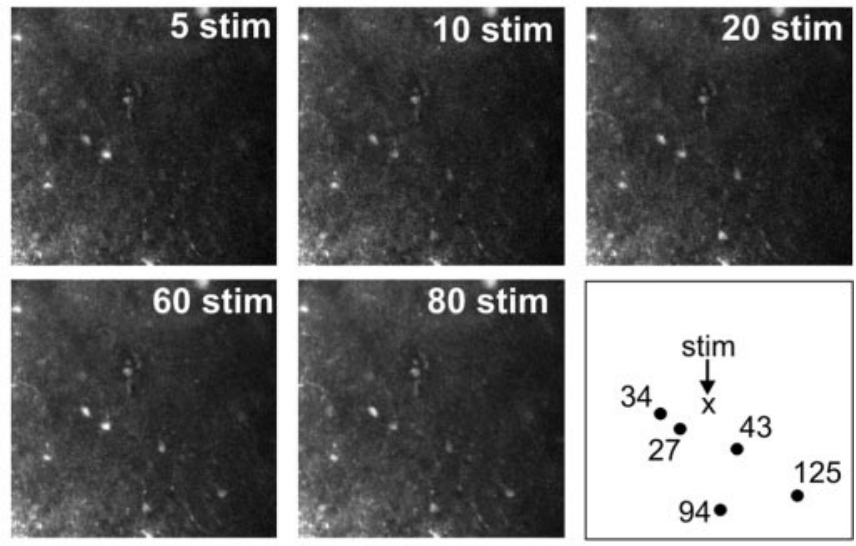

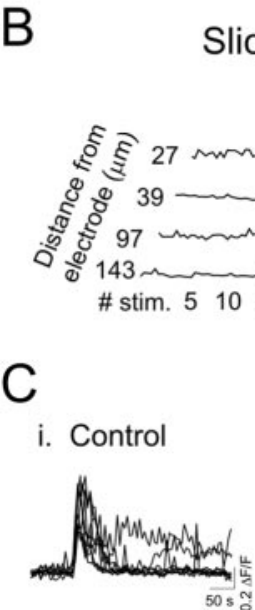

iii. Cadmium

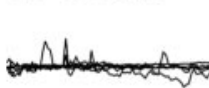

ii. TTX

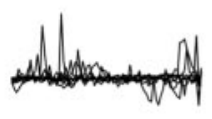

v. BoToxE

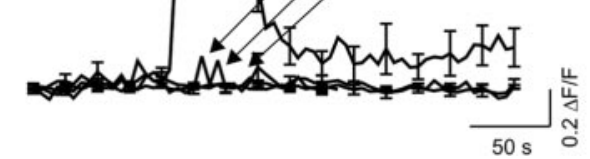

Figure 8. Astrocytes are activated by vesicular release during local electrical stimulation. A, Confocal images of fluo-4-loaded astrocytes in hippocampal slices. A glass electrode is placed in the center of the field of view (stim), and trains of stimuli (number indicated on image) are delivered to the slice at $30 \mathrm{~Hz}$. The concentric circles are $50 \mu \mathrm{m}$ apart. The final panel identifies astrocytes itored and the number of micrometers they are from the electrode. Astrocytes appear to be confined to the bottom left of the

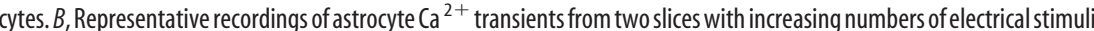
The experiment presented in $A$. C, Ten superimposed traces showing the change in intracellular $\mathrm{Ca}^{2+}$ for astrocytes under control conditions (i) and in the presence of $1 \mu \mathrm{M} \mathrm{TTX} \mathrm{(ii),} 10 \mu \mathrm{m}$ cadmium (iii), and $20 \mu \mathrm{g} / \mathrm{ml}$ botulinum toxin E (iv). D, Average traces for treatments indicated in C(TTX: $n=36,9$ slices; cadmium: $n=46,6$ slices; botulinum toxin E: $n=35,5$ slices).

latency between the time of the stimulus and the peak of the $\mathrm{Ca}^{2+}$ increase in astrocytes were smaller for astrocytes close to the electrode (Fig. 9Ci) and longer for astrocytes up to $200 \mu \mathrm{m}$ away (Fig. 9Cii), indicative of a signal that spreads out from the site of stimulation (all data points are shown in Fig. 10A, control and averages are shown in $B$ ). This is reminiscent of the spread in ATP levels from a point source in retinal slices and cultured astrocytes (Guthrie et al., 1999; Newman, 2001b; Koizumi et al., 2003). We next tested the hypothesis that the spread of astrocyte activation evoked by electrical stimulation in the center of the field of view was attributable to ATP acting on astrocyte P2Y receptors and/or glutamate acting on metabotropic glutamate receptors. The peak $\Delta F / F$ for astrocyte $\mathrm{Ca}^{2+}$ increases in the antagonists or under control conditions was similar (Fig. $9 E$ ) but significantly briefer in the presence of PPADS $(10 \mu \mathrm{M})$ and MRS2179 $(30 \mu \mathrm{M})$ than in 

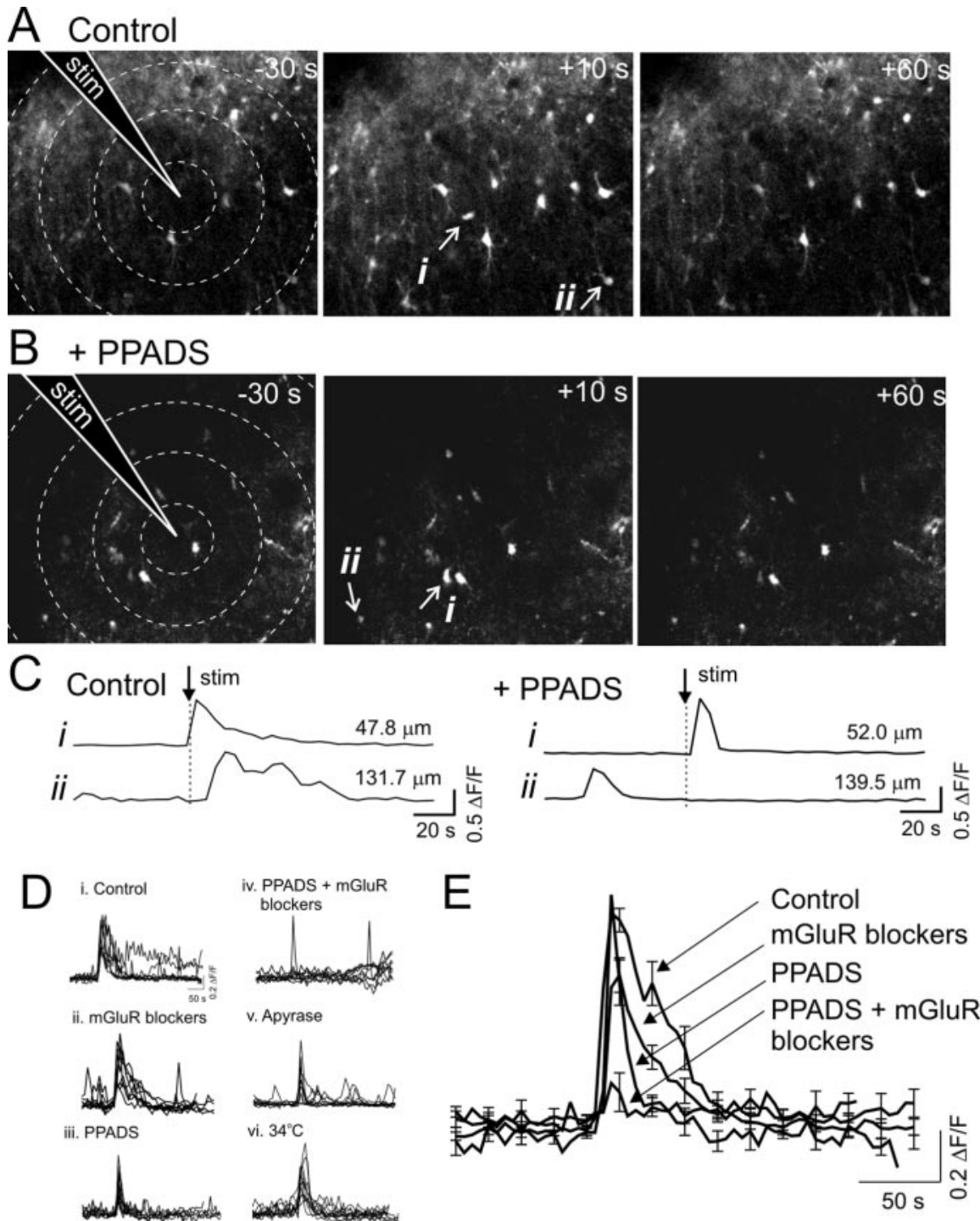

v. Apyrase
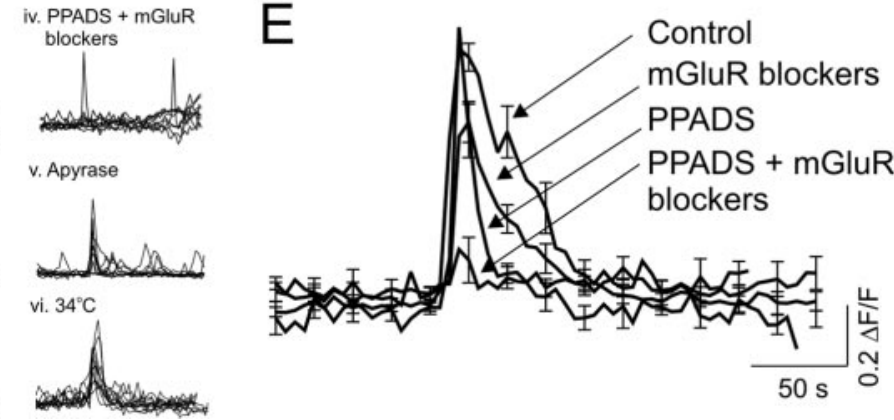

Figure 9. Astrocyte $\mathrm{Ca}^{2+}$ transients evoked by electrical stimulation (stim). $A, B$, Confocal images of fluo-4-AM-loaded hippocampal slices $30 \mathrm{sec}$ before field stimulation and 10 and $30 \mathrm{sec}$ after stimulation under control conditions $(A)$ and in the presence of $30 \mu \mathrm{m} \operatorname{PPADS}(B)$. The position of the stimulating electrode is shown on a grid of $25 \mu \mathrm{m}$ spacing. $C$, Example $\mathrm{Ca}^{2+}$ traces for two astrocytes $(i, i i$ indicated in $A, B)$ and the distances from the stimulating electrode under control conditions and in the presence of PPADS. D, Ten superimposed traces showing change in intracellular $\mathrm{Ca}^{2+}$ for astrocytes in control $(i)$, in the presence of mGluR antagonists (ii), PPADS (iii), and both mGluR antagonists and PPADS (iv). Note that the transients are briefer in the presence of PPADS and completely blocked in the presence of both PPADS and the mGluR antagonists. Superimposed traces are also shown for slices treated with $20 \mathrm{U} / \mathrm{ml}$ apyrase $(v)$ and for experiments conducted at $34^{\circ} \mathrm{C}(\mathrm{vi})$. Average astrocyte transients for the indicated treatments are shown in $E$.

control (Fig. 9D,E). Furthermore, whereas in control slices, $\mathrm{Ca}^{2+}$ changes could be measured in astrocytes $\sim 200 \mu \mathrm{m}$ from the stimulating electrode (Fig. 10A,B) (supplemental material, available at www.jneurosci.org), in the presence of PPADS and MRS2179, astrocytes only responded in a region half this size at $\sim 100 \mu \mathrm{m}$ (Figs. $9 B i, i i, 10 A, B$ ) (supplemental material, available at www.jneurosci.org). Similar data were gathered from slices treated with extracellular apyrase $(10 \mathrm{U} / \mathrm{ml})$, a nucleotidase that is expected to hydrolyze any released ATP (Fig. 9D). The residual astrocyte responses that remain in the presence of $\mathrm{P}_{2} \mathrm{Y}_{1}$ receptor antagonists are likely caused by activation of group I metabotropic glutamate receptors (Porter and McCarthy, 1996). Consistent with this, treatment of slices with the group I mGluR antagonists MPEP and LY367358 (100 $\mu \mathrm{M})$ significantly reduced the peak $\Delta F / F$ (41 astrocytes, 7 slices) (Fig. $9 D, E)$, and cotreatment with PPADS completely blocked evoked astrocyte activation in $95 \%$ of cells (3 of 55 astrocytes from 9 slices still responded). From these data, we suggest that the triggering stimulus to astrocytes is likely to be vesicular release of glutamate and ATP from presynaptic terminals in s.r. This is readily seen in the representative traces in Figure 9D, averaged data in Figure $9 E$, and was further quantified by integrating the area under the $\mathrm{Ca}^{2+}$ transients (Fig. 10D). In the most straightforward explanation, the astrocyte signal appears to be propagated by a mixture of glutamate acting on astrocytes within $100 \mu \mathrm{m}$ of the stimulus and by ATP to more distant astrocytes $(200 \mu \mathrm{m})$ (Fig. 10E).

\section{Endogenous activation of $\mathrm{P} 2 \mathrm{Y}$ receptors on astrocytes increases synaptic inhibition}

If endogenous ATP activates astrocyte P2Y receptors over $\sim 200 \mu \mathrm{m}$ distance scales (Figs. 9, 10), then does this affect inhibitory synaptic activity onto interneurons? To address this, we monitored the frequency of spontaneous IPSCs in $30 \mathrm{sec}$ windows before and after electrical stimulation using conditions identical to those that caused excitation of astrocytes (Figs. 9, 10). We expressed the data as the ratio of the number of IPSCs before and after stimulation (the facilitation ratio) (Fig. 11 $A, B$ ) under control conditions and during pharmacological treatments to affect ATP signaling. The facilitation ratio was significantly reduced when $\mathrm{P} 2 \mathrm{Y}$ receptors were blocked with PPADS at $23^{\circ} \mathrm{C}$ (Fig. $\left.11 \mathrm{Bi}\right)(1.06 \pm$ 0.04 to $0.84 \pm 0.04 ; n=10 ; p<0.05)$ and at the more physiological temperature of $34^{\circ} \mathrm{C}$ (Fig. 11 Bii) $(1.11 \pm 0.06$ to $0.91 \pm 0.05 ; n=7 ; p<0.05)$. We also used complimentary approaches to block endogenous ecto-nucleotidases with 6-N,N-diethyl- $\beta$ - $\gamma$-dibromomethylene-D-ATP (ARL67156) and therefore presumably increase extracellular ATP levels and used apyrase $(20 \mathrm{U} / \mathrm{ml})$ to cleave any released ATP. In experiments conducted at $34^{\circ} \mathrm{C}$, ARL67156 significantly increased the facilitation ratio by $25 \%$ (Fig. 11 Biii) $(0.95 \pm 0.02$ to $1.20 \pm 0.05 ; n=8 ; p<0.05)$. In experiments at $34^{\circ} \mathrm{C}$, apyrase decreased the facilitation ratio in 9 of 12 interneurons investigated (Fig. $11 \mathrm{Biv}$ ). Although the pooled data from all 12 interneurons treated with apyrase did not reach statistical significance $(p>0.05)$, statistical significance was obtained (from $1.11 \pm 0.01$ to $1.02 \pm 0.01 ; n=9 ; p<0.05$ ) by removing the two experiments where the facilitation ratio increased. The variability in the effect of apyrase may be explained by the fact that it is a protein, for which penetration may vary between slices and also because apyrase is expected to generate ADP, a potent agonist of $\mathrm{P}_{2} \mathrm{Y}_{1}$ receptors (Zimmermann, 1999). 

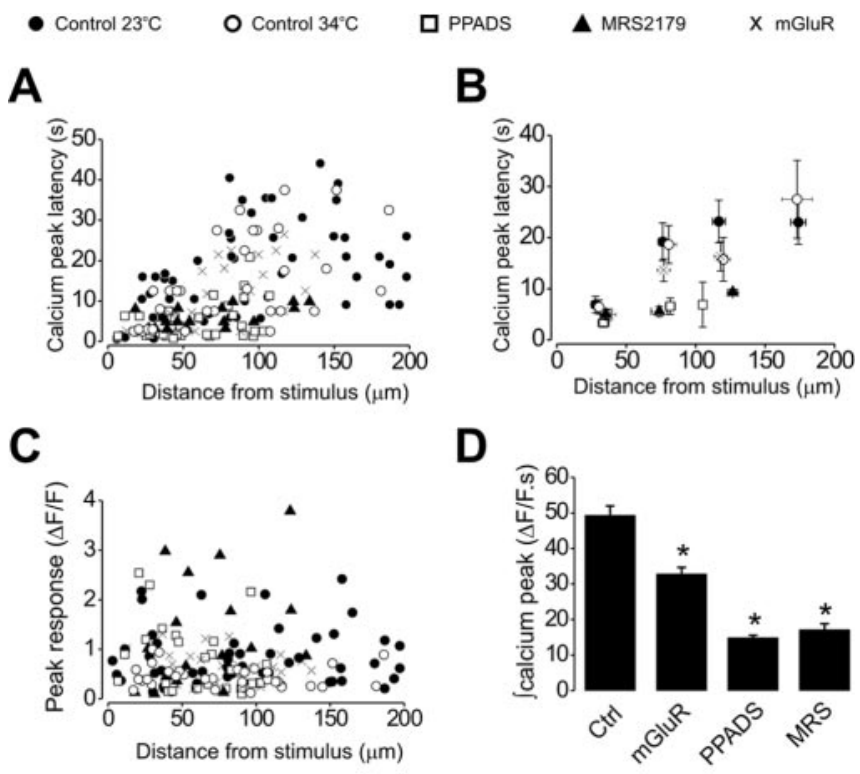

$\mathbf{E}$

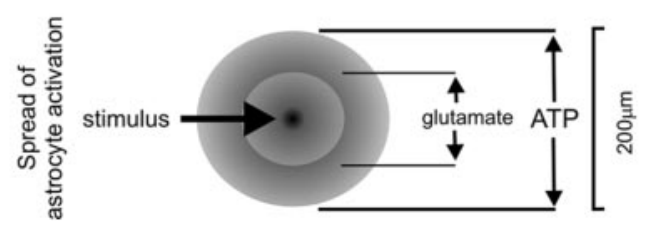

Figure 10. Properties of astrocyte $\mathrm{Ca}^{2+}$ transients evoked by electrical stimulation. Pooled astrocyte data for control (9 slices, 54 astrocytes), PPADS treated (9 slices, 29 astrocytes), MRS2179 treated (4 slices, 17 astrocytes), mGluR antagonist treated (7 slices, 41 astrocytes), and control experiments conducted at $34^{\circ} \mathrm{C}(6$ slices, 34 astrocytes). $A$, Scatter plot of calcium peak response latency (time from beginning of spike train to peak of $\mathrm{Ca}^{2+}$ transient) against distance from stimulus region. $B$, Averaged data for $50 \mu \mathrm{m}$ bins. C, Peak astrocyte $\Delta F / F$ against distance from stimulus region. $D$, Integrated astrocyte responses evoked by electrical stimulation. $E$, Summary diagram of the results shown in $A-E$. In control slices, astrocytes within a radius of $200 \mu \mathrm{m}$ show an increase in $\mathrm{Ca}^{2+}$ during electrical stimulation; however, when P2Y receptors were blocked, this radius was reduced to $100 \mu \mathrm{m}$, implying that endogenously released ATP activates P2Y receptors to allow astrocyte excitation to spread to large distance scales.

Although all of our experiments were performed with adenosine receptors blocked, we also determined whether adenosine had any role to play in the responses described in Figure 11. We found no significant difference in the facilitation ratio after $15 \mathrm{~min}$ incubations in $10 \mu \mathrm{M}$ DPCPX $(1.08 \pm 0.04$ to $1.06 \pm 0.04 ; p>0.05$; $n=8$ ). We propose that $20 \%$ of the IPSCs impacting on interneurons after a period of electrical stimulation were caused by ATP release from astrocytes acting on interneuron $\mathrm{P}_{2} \mathrm{Y}_{1}$ receptors to increase their excitability (Figs. 1, 3).

We next sought more direct evidence for the hypothesis that ATP released from astrocytes activates P2Y receptors on interneurons to increase their excitability. To this end, we used thrombin ( $10 \mathrm{U} / \mathrm{ml}$ for $5 \mathrm{~min}$ ) to selectively activate astrocytes only (Ubl and Reiser, 1997; Newman, 2003b), imaged $\mathrm{Ca}^{2+}$ within astrocytes, and recorded synaptic events from nearby interneurons $(<200 \mu \mathrm{m}$ away). Thrombin evoked increases in the frequency and amplitude of $\mathrm{Ca}^{2+}$ oscillations in astrocytes (Fig. 12A), which were similar to those evoked by electrical stimulation (Figs. $8,9)$. The changes in astrocytes were accompanied by increases in the frequency and amplitude of sIPSCs recorded from interneurons (Fig. 12C), which were also similar to the effect of exogenous ATP (Fig. $3 A$ ) and to the effect of electrical stimulation (Fig.

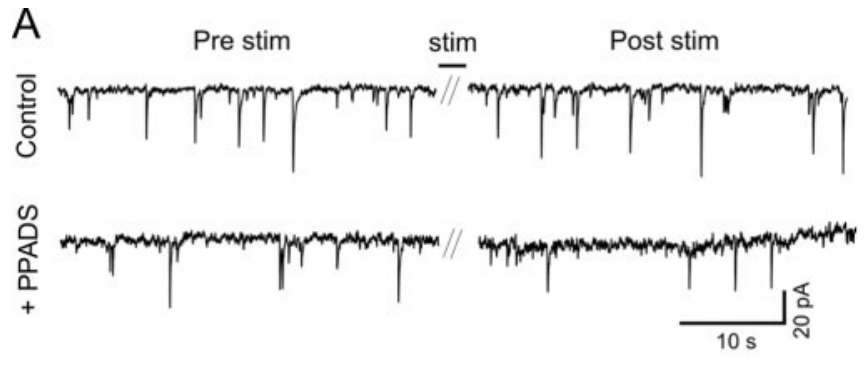

B
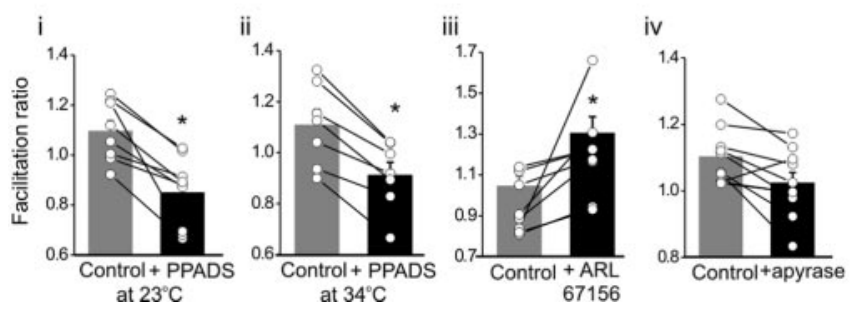

Figure 11. Electrical stimulation increases GABAergic sIPSCs onto interneurons. $A$, Interneurons were voltage clamped at $-60 \mathrm{mV}$ with a $\mathrm{KCl}$-based internal solution allowing visualization of inward GABAergic synaptic events. A train of 100 pulses (7-15 $\mu \mathrm{A}$; indicated by the gap in the trace) at $30 \mathrm{~Hz}$ was applied from a monopolar electrode. A representative trace is shown in $A$ where the bar indicates the stimuli and 30 sec of IPSCs are shown before (Pre stim) and after (Post stim) the stimulus. The slice was then perfused with $30 \mu \mathrm{m}$ PPADS for $15 \mathrm{~min}$, and the protocol was repeated. The number of IPSCS in $30 \mathrm{sec}$ windows after the train divided by the number before the train is given as the facilitation ratio in $B$, which was decreased in PPADS at $23^{\circ} \mathrm{C}$, PPADS at $34^{\circ} \mathrm{C}$, and in the presence of $20 \mathrm{U} / \mathrm{ml}$ apyrase at $34^{\circ} \mathrm{C}$. Treatment with the ecto-nucleotidase inhibitor ARL67156 at $34^{\circ} \mathrm{C}$ significantly enhanced the facilitation ratio.

$11 A, B)$. If thrombin-evokes ATP release from astrocytes that then activates $\mathrm{P} 2 \mathrm{Y}_{1}$ receptors on interneurons, then blocking $\mathrm{P}_{2} \mathrm{Y}_{1}$ receptors should block the thrombin-evoked increase in sIPSCs in interneurons but spare the increase in astrocyte $\mathrm{Ca}^{2+}$ oscillations evoked by thrombin. Indeed, this was the case: the thrombin-evoked increase in IPSCs was abolished with PPADS and MRS2179 (Fig. 12C,D), whereas $\mathrm{Ca}^{2+}$ oscillations in astrocytes were spared (Fig. $11 \mathrm{~B}$ ). These data indicate that PPADS and MRS2179 do not affect the ability of thrombin to excite astrocytes but impair its ability to increase the frequency of sIPSC onto interneurons presumably because this latter effect is mediated by thrombin-evoked ATP release from astrocytes that then activates $\mathrm{P} 2 \mathrm{Y}$ receptors on nearby interneurons. Consistent with this, thrombin depolarized interneurons slightly $(+1.9 \pm 0.4 \mathrm{mV} ; n=$ 6) but, more importantly, increased their excitability (Fig. 11E) rather like the effect of exogenous ATP (Fig. 1D,F), such that they fired more action potentials for lower levels of depolarizing current. This effect of thrombin was blocked by PPADS (Fig. $11 F)(n=6)$. Thus, by using thrombin to selectively activate astrocytes, we could mimic the PPADS- and MRS2179-sensitive effects of electrical stimulation and of exogenous ATP on interneurons. The effects of endogenous ATP release (electrical stimulation and thrombin application) were smaller than those for bath application of ATP.

\section{$\mathrm{P} 2 \mathrm{Y}_{1}$-expressing interneurons are decorated with astrocytes and their processes}

Our data suggest endogenous regulation of interneuron excitability by astrocytes through release of ATP. We next investigated the relationship between astrocytes and interneurons in s.r. Fixed coronal hippocampal sections $(30 \mu \mathrm{m})$ were stained for GFAP. 


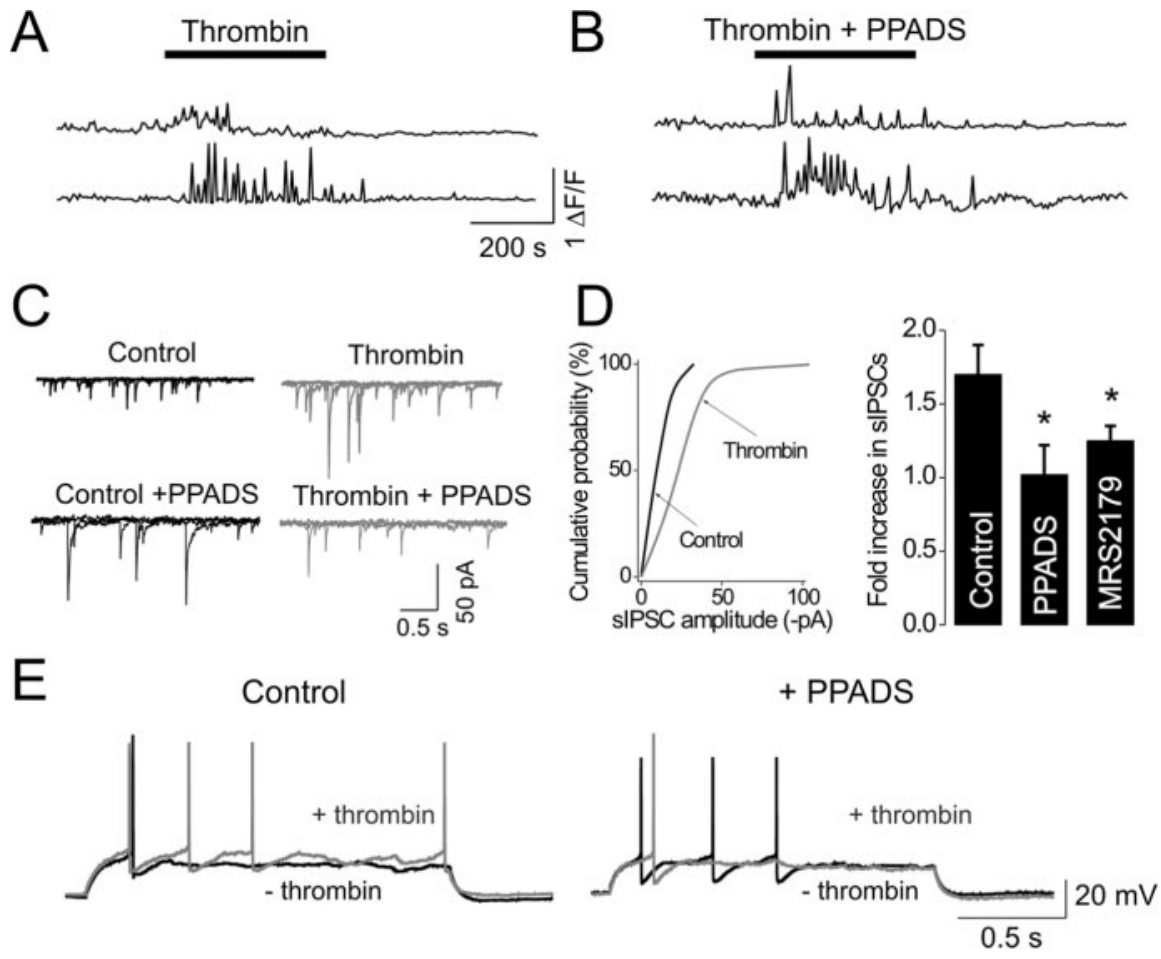

Figure 12. Direct astrocyte activation with thrombin increases GABAergic sIPSCS onto interneurons. Two examples of thrombin $(10 \mathrm{U} / \mathrm{ml})$ induced $\mathrm{Ca}^{2+}$ oscillations in astrocytes under control conditions $(A)$ and in the presence of PPADS $(B)$. C, Representative current traces of spontaneous IPSCs before and during thrombin perfusion (3 superimposed traces of 3 sec duration). Bottom traces are from a slice incubated in PPADS before and in the presence of thrombin. $D$, Left graph, Cumulative probability plot of sIPSC amplitude in control conditions and during thrombin. Right, Fold increase in the frequency of sIPSCs evoked by thrombin alone (control; $n=8$ ) or with thrombin in the presence of PPADS $(n=7)$ or MRS2179 $(n=5)$ ). $E$, Left, Example traces from an s.r. interneuron before and during thrombin. Note that there are more action potentials in thrombin. Right, Example traces from an s.r. interneuron before and during thrombin with PPADS present throughout. Note that there are fewer action potentials in thrombin when PPADS is present (see Results for additional details).

Interestingly, the density of astrocytes was highest in s.r.-s.l-m., and s.o. and lowest in the pyramidal cell layer (Fig. 13A), a pattern that is reminiscent of $\mathrm{P}_{2} \mathrm{Y}_{1}$ receptor expression within interneurons (Fig. $4 E$ ). Indeed, higher magnification costaining experiments in s.r.-s.l-m. (with GFAP in green, and P2 $\mathrm{Y}_{1}$ in red) show that $\mathrm{P}_{2} \mathrm{Y}_{1}$ receptor-expressing interneurons are surrounded by astrocytes with highly branched morphologies (Fig. 13B). We next attempted to determine the number of astrocytes that may contact a given interneuron that responded to ATP with an inward current (supplemental material, available at www.jneurosci.org) by filling interneurons with biocytin through the patch pipette, staining for GFAP, and visualizing interneuron dendritic arbors with streptavidin-conjugated Alexa-488 (Fig. 13C). Interneuron dendrites contacted $27 \pm 5$ astrocytes in $200 \mu \mathrm{m}$ thick sections ( $n=5$ interneurons) and were highly decorated with multiple GFAP-positive processes. It is important to note that GFAP is absent from the periphery and fine processes of astrocytes (Bushong et al., 2002; Wilhelmsson et al., 2004). Therefore, the true extent of spatial interactions between the interneurons and astrocytes is likely to be much higher than the present experiments indicate (we estimate by a factor of at least 3.4 from the work of Wilhelmsson et al., 2004). Nonetheless, the close relationship between $\mathrm{P}_{2} \mathrm{Y}_{1}$ receptor-expressing interneurons and astrocytes (Fig. 13) provides a framework to interpret our data indicating ATP-mediated signaling between these cell types.

\section{Discussion}

Receptors for ATP are found in the hippocampus, and ATP is released from neurons and astrocytes. Therefore, it is important to understand the effects of ATP on single neurons and intact neuronal networks. The main finding of the present study is that endogenously released ATP acts on $\mathrm{P}_{2} \mathrm{Y}_{1}$ receptors on hippocampal CA1 interneurons and astrocytes to cause interneuron excitation leading to increased GABAergic synaptic inhibition onto output pyramidal neurons. As far as we know, this is the first evidence for physiological activation of $\mathrm{P} 2 \mathrm{Y}$ receptors by endogenously released ATP in an intact brain circuit. The findings reveal several facets that may be predictive for ATP signaling in the brain.

For exogenous applications of ATP, we attribute a large $(\sim 80 \%)$ component of the interneuron depolarization to activation of a nonselective cationic conductance. This conductance shares characteristics with transient receptor potential (TRP) channels, which are known to be expressed in the hippocampus ( $\mathrm{Li}$ et al., 1999; Strubing et al., 2001) and activated by Gq-coupled receptors, but more selective channel blockers are needed to determine the identity of the channels that are opened when $\mathrm{P} 2 \mathrm{Y}_{1}$ receptors are activated in interneurons. It is interesting to note, however, that $\mathrm{P} 2 \mathrm{Y}$ receptors are known to modulate vanilloid (TRPV1) channels in sensory neurons (Tominaga et al., 2001; Moriyama et al., 2003) and to activate a nonselective cationic conductance intrinsic to oocytes (O'Grady et al., 1996; Lee et al., 2003). The responses described in this study are similar to the latter findings in that both are unaffected by intracellular GDP $\beta$ S, implying direct activation of ion channels by $\mathrm{P}_{2} \mathrm{Y}_{1}$ receptors (O'Grady et al., 1996; Lee et al., 2003). A smaller $(\sim 20 \%)$ component of the response to exogenous ATP may be caused by suppression of a $\mathrm{K}^{+}$conductance. This is in keeping with extensive studies of heterologously expressed $\mathrm{P} 2 \mathrm{Y}$ receptors that modulate distinct types of channels, including potassium channels (von Kugelgen and Wetter, 2000). The residual response that persists when ATP has been washed from the bath appears to be caused by suppression of a potassium conductance by endogenously released glutamate acting on group I metabotropic glutamate receptors. Thus, the cellular effect of exogenous ATP at interneurons is surprisingly complex, recalling similar responses with muscarinic agonists in locus ceruleus neurons (Shen and North, 1992) and hippocampal interneurons (McQuiston and Madison, 1999) that also result from the concomitant activation and suppression of distinct transmembrane conductances. Regardless, ATP activation of $\mathrm{P}_{2} \mathrm{Y}_{1}$ receptors on interneurons leads to profound interneuron excitation.

Our data with electrical stimulation, and selective activation of astrocytes, show that ATP and glutamate released from within brain slices activates endogenous $\mathrm{P} 2 \mathrm{Y}$ and $\mathrm{mGluR}$ receptors on 

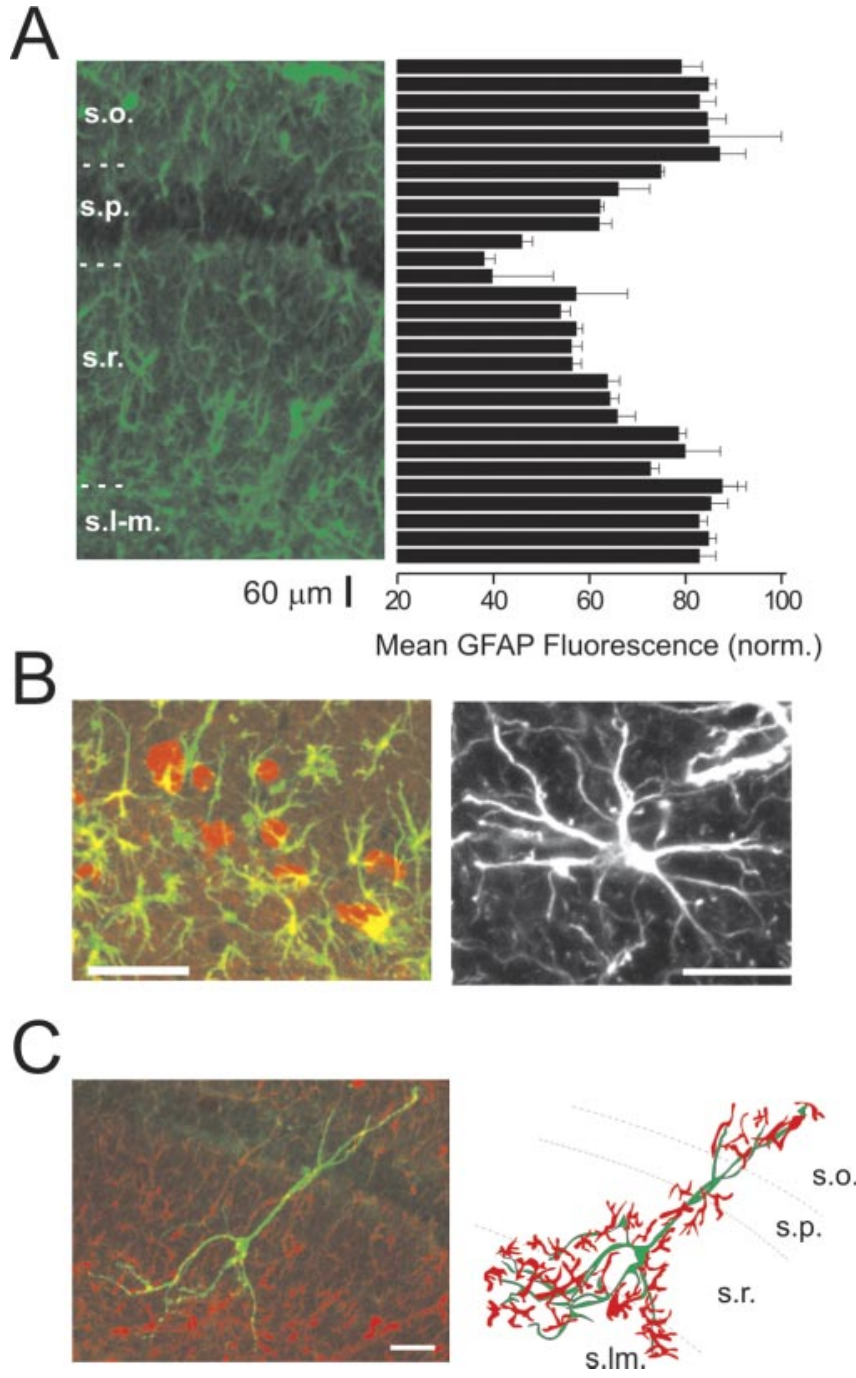

Figure 13. Relationship between astrocytes and interneurons. $A$, Fluorescence micrograph of GFAP-labeled astrocytes (green) reveals that astrocytes are most abundant in s.o., s.r., and s.I-m. Scale bar, $30 \mu \mathrm{m}$. The distribution of GFAP fluorescence was quantified in $15-\mu \mathrm{m}$-thick regions of interest oriented horizontally across the image. The average intensity from these regions from five different hippocampal sections was normalized (norm.) to the maximum intensity for each slice and plotted as a bar graph on the right. $B$, Higher-magnification image of P2Y -labeled interneurons (red) on the s.r.-s.l-m. border with surrounding GFAP-labeled astrocyte processes (green). Scale bar, $30 \mu \mathrm{m}$. Left, A confocal image of a GFAP-labeled astrocyte at high magnification. Scale bar, $15 \mu \mathrm{m}$. C, Confocal image of a biocytin-filled interneuron (green) with GFAP-immunoreactive astrocytes (red). This interneuron was sketched on the right from a confocal Z-stack of images. GFAP-labeled astrocytes that made contact with the interneuron were traced in red. Scale bar, $50 \mu \mathrm{m}$. s.p., Stratum pyramidale.

astrocytes. We propose that glutamatergic terminals in stratum radiatum release glutamate and ATP during electrical stimulation. This initiates a wave of astrocyte activation mediated by ATP that spreads to a sphere of $\sim 200 \mu \mathrm{m}$ diameter. Viewed from this perspective, astrocyte signaling mediated by ATP acting on $\mathrm{P} 2 \mathrm{Y}$ receptors has the potential to affect neuronal function over much larger distance scales than fast synaptic ATP signaling mediated by P2X channels, which because of the rarity and small size of ATP EPSCs is probably only restricted to a few spines (Khakh, 2001). Moreover, because $\mathrm{P}_{2} \mathrm{Y}_{1}$ receptors have high affinity for ADP and ATP, this implies that astrocyte P2Y receptors may respond even when ATP has been degraded by ectoATPases, whereas P2X channel responses would be curtailed (Zimmer- mann, 1994). Similar mechanisms may be engaged during pathological conditions, such as ischemia, that are known to release ATP (Lutz and Kabler, 1997; Braun et al., 1998).

Although classically thought to mediate a supportive role, there is now increasing evidence to suggest that astrocytes actively participate in information processing by affecting intrinsic properties of synapses (Haydon, 2001; Newman, 2003a). Astrocytes are appropriately positioned to regulate interneurons in the hippocampus. We used increased intracellular $\mathrm{Ca}^{2+}$ levels as a fingerprint for astrocyte excitation, because $\mathrm{Ca}^{2+}$ increases are known to release signaling molecules from astrocytes. It is noteworthy that the numbers of astrocytes loaded with Fluo-4-AM in live slices were smaller than those that stained for GFAP in fixed sections, implying that our $\mathrm{Ca}^{2+}$ imaging measurements report only a fraction of the ongoing astrocyte activity within the slice. Presumably, this indicates that the true response is even more robust than our measurements allow us to infer. ATP released from glia clearly hyperpolarizes neurons in the retina (Newman, 2003 b), and ATP released from astrocytes in culture has also been suggested to suppress glutamatergic synapses via presynaptic P2Y receptors (Koizumi et al., 2003; Zhang et al., 2003). Our experiments build on these observations and provide evidence for a $\mathrm{P}_{2} \mathrm{Y}_{1}$ receptor-mediated slow excitation of interneurons that relies on both interneurons and astrocytes.

For the most part, we used local electrical stimulation within s.r. or stimulation of SC and PP inputs to evoke responses within astrocytes and interneurons to determine whether ATP has a contributory role. We emphasize that the parameters we used for stimulation are neither gross nor intense, because similar protocols have been used extensively in the study of astrocyte signaling and in the induction of synaptic plasticity in the hippocampus (Regehr et al., 1989; Regehr and Tank, 1990; Porter and McCarthy, 1996). Moreover, we bolstered our key findings with thrombin as a specific pharmacological approach to activate astrocytes (Puro and Stuenkel, 1995; Ubl and Reiser, 1997; Newman, 2003b) and measured the ensuing consequences for interneurons. Together, these and other data (Guthrie et al., 1999; Fields and Stevens, 2000; Newman, 2001a,b, 2003a,b; Koizumi et al., 2003; Zhang et al., 2003) imply that astrocyte-derived ATP may affect neuronal function, but of course in the future it will be important to determine the precise in vivo physiological settings in which this occurs. We cannot glean this from our in vitro experiments, but from this perspective spectacular breakthroughs on ATP-mediated interactions between peripheral neurons and Schwann cells may prove to be portentous (Fields and Stevens-Graham, 2002; Fields, 2004). Interestingly, recent work in vivo has demonstrated the existence of coordinated astrocyte $\mathrm{Ca}^{2+}$ oscillations in superficial layers of the rat cortex (Hirase et al., 2004). Astrocyte $\mathrm{Ca}^{2+}$ activity was increased when neuron excitability was elevated by blocking $\mathrm{GABA}_{\mathrm{A}}$ channels, suggesting that neuron-astrocyte communication occurs in vivo (Hirase et al., 2004). In future work, it may be possible to repeat these in vivo experiments for the stratum radiatum region of the mouse hippocampus and relate astrocyte activity to the in vitro data presented in this study.

Our electrophysiological experiments provide strong evidence to indicate that the net effect of ATP at interneurons is a depolarization that leads to increased $\mathrm{GABA}_{\mathrm{A}}$ receptor-mediated synaptic inhibition. The essential features of our data are summarized in a diagram (supplemental material, available at www.jneurosci.org). Our previous work suggested that ATP acts on $\mathrm{P}_{2} \mathrm{X}_{2}$ channels on Schaffer collateral terminals to increase excitatory synaptic transmission onto interneurons (Khakh et al., 
2003). The present findings extend these data to show that postsynaptic $\mathrm{P}_{2} \mathrm{Y}_{1}$ receptors mediate a novel slow form of interneuron excitation, which may lead to persistent increases in interneuron excitability. Our data suggest that astrocytes release and propagate a wave of ATP, which activates $\mathrm{P}_{2} \mathrm{Y}_{1}$ receptors to profoundly affect network activity. Together with our previous work on $\mathrm{P} 2 \mathrm{X}$ receptors, we suggest that distinct purinergic receptors act in concert to increase interneuron excitability and reduce pyramidal neuron excitability. Given that interneurons contribute to information processing (McBain and Fisahn, 2001), these data provide a rationale to study cognitive and behavioral responses in mice lacking distinct $\mathrm{P} 2 \mathrm{X}$ and $\mathrm{P} 2 \mathrm{Y}$ receptors.

\section{References}

Araque A, Carmignoto G, Haydon PG (2001) Dynamic signalling between astrocytes and neurons. Annu Rev Physiol 63:795-813.

Bertrand S, Lacaille JC (2001) Unitary synaptic currents between lacunosum-moleculare interneurones and pyramidal cells in rat hippocampus. J Physiol (Lond) 532:369-384.

Braun N, Zhu Y, Krieglstein J, Culmsee C, Zimmermann H (1998) Upregulation of the enzyme chain hydrolyzing extracellular ATP after transient forebrain ischemia in the rat. J Neurosci 18:4891-4900.

Burnstock G (1972) Purinergic nerves. Pharmacol Rev 24:509-581.

Burnstock G (2004) Cotransmission. Curr Opin Pharmacol 4:47-52.

Bushong EA, Martone ME, Jones YZ, Ellisman MH (2002) Protoplasmic astrocytes in CA1 stratum radiatum occupy separate anatomical domains. J Neurosci 22:183-192.

Fam SR, Gallagher CJ, Salter MW (2000) P2Y(1) purinoceptor-mediated $\mathrm{Ca}^{2+}$ signaling and $\mathrm{Ca}^{2+}$ wave propagation in dorsal spinal cord astrocytes. J Neurosci 20:2800-2808.

Fields RD (2004) The other half of the brain. Sci Am 290:54-61.

Fields RD, Stevens B (2000) ATP: an extracellular signaling molecule between neurons and glia. Trends Neurosci 23:625-633.

Fields RD, Stevens-Graham B (2002) New insights into neuron-glia communication. Science 298:556-562.

Guthrie PB, Knappenberger J, Segal M, Bennett MV, Charles AC, Kater SB (1999) ATP released from astrocytes mediates glial calcium waves. J Neurosci 19:520-528.

Haydon PG (2001) GLIA: listening and talking to the synapse. Nat Rev Neurosci 2:185-193.

Hirase H, Qian L, Bartho P, Buzsaki G (2004) Calcium dynamics of cortical astrocytic networks in vivo. PLoS Biol 2:0494-0499.

Khakh BS (2001) Molecular physiology of P2X receptors and ATP signalling at synapses. Nat Rev Neurosci 2:165-174.

Khakh BS, Gittermann D, Cockayne DA, Jones A (2003) ATP modulation of excitatory synapses onto interneurons. J Neurosci 23:7426-7437.

Koizumi S, Fujishita K, Tsuda M, Shigemoto-Mogami Y, Inoue K (2003) Dynamic inhibition of excitatory synaptic transmission by astrocytederived ATP in hippocampal cultures. Proc Natl Acad Sci USA 100:11023-11028.

Krause M, Offermanns S, Stocker M, Pedarzani P (2002) Functional specificity of $\mathrm{G} \alpha \mathrm{q}$ and $\mathrm{G} \alpha 11$ in the cholinergic and glutamatergic modulation of potassium currents and excitability in hippocampal neurons. J Neurosci 22:666-673.

Lazarowski ER, Boucher RC, Harden TK (2003) Mechanisms of release of nucleotides and integration of their action as P2X- and P2Y-receptor activating molecules. Mol Pharmacol 64:785-795.

Lee SY, Wolff SC, Nicholas RA, O'Grady SM (2003) P2Y receptors modulate ion channel function through interactions involving the C-terminal domain. Mol Pharmacol 63:878-885.

Li HS, Xu XZ, Montell C (1999) Activation of a TRPC3-dependent cation current through the neurotrophin BDNF. Neuron 24:261-273.

Liu QS, Xu Q, Arcuino G, Kang J, Nedergaard M (2004) Astrocyte-mediated activation of neuronal kainate receptors. Proc Natl Acad Sci USA 101:3172-3177.

Lutz PL, Kabler S (1997) Release of adenosine and ATP in the brain of the freshwater turtle (Trachemys scripta) during long-term anoxia. Brain Res 769:281-286.

Mannaioni G, Marino MJ, Valenti O, Traynelis SF, Conn PJ (2001) Metabotropic glutamate receptors 1 and 5 differentially regulate CA1 pyramidal cell function. J Neurosci 21:5925-5934.
Matyas F, Freund TF, Gulyas AI (2004) Immunocytochemically defined interneuron populations in the hippocampus of mouse strains used in transgenic technology. Hippocampus 14:460-481.

McBain CJ, Fisahn A (2001) Interneurons unbound. Nat Rev Neurosci 2:11-23.

McQuiston AR, Madison DV (1999) Muscarinic receptor activity has multiple effects on the resting membrane potential of CA1 hippocampal interneurons. J Neurosci 19:5693-5702.

Moore D, Chambers J, Waldvogel H, Faull R, Emson P (2000) Regional and cellular distribution of the $\mathrm{P} 2 \mathrm{Y}(1)$ purinergic receptor in the human brain: striking neuronal localisation. J Comp Neurol 421:374-384.

Moran-Jimenez MJ, Matute C (2000) Immunohistochemical localization of the P2Y(1) purinergic receptor in neurons and glial cells of the central nervous system. Brain Res Mol Brain Res 78:50-58.

Moriyama T, Iida T, Kobayashi K, Higashi T, Fukuoka T, Tsumura H, Leon C, Suzuki N, Inoue K, Gachet C, Noguchi K, Tominaga M (2003) Possible involvement of P2Y2 metabotropic receptors in ATP-induced transient receptor potential vanilloid receptor 1-mediated thermal hypersensitivity. J Neurosci 23:6058-6062.

Moro S, Guo D, Camaioni E, Boyer JL, Harden TK, Jacobson KA (1998) Human $\mathrm{P}_{2} \mathrm{Y}_{1}$ receptor: molecular modeling and site-directed mutagenesis as tools to identify agonist and antagonist recognition sites. J Med Chem 41:1456-1466.

Newman EA (2001a) Propagation of intercellular calcium waves in retinal astrocytes and Muller cells. J Neurosci 21:2215-2223.

Newman EA (2001b) Calcium signaling in retinal glial cells and its effect on neuronal activity. Prog Brain Res 132:241-254.

Newman EA (2003a) New roles for astrocytes: regulation of synaptic transmission. Trends Neurosci 26:536-542.

Newman EA (2003b) Glial cell inhibition of neurons by release of ATP. J Neurosci 23:1659-1666.

North RA (2002) Molecular physiology of P2X receptors. Physiol Rev 82:1013-1067.

O’Grady SM, Elmquist E, Filtz TM, Nicholas RA, Harden TK (1996) A guanine nucleotide-independent inwardly rectifying cation permeability is associated with $\mathrm{P}_{2} \mathrm{Y}_{1}$ receptor expression in Xenopus oocytes. J Biol Chem 271:29080-29087.

Pankratov Y, Castro E, Miras-Portugal MT, Krishtal O (1998) A purinergic component of the excitatory postsynaptic current mediated by $\mathrm{P} 2 \mathrm{X}$ receptors in the CA1 neurons of the rat hippocampus. Eur J Neurosci 10:3898-3902.

Parpura V, Haydon PG (2000) Physiological astrocytic calcium levels stimulate glutamate release to modulate adjacent neurons. Proc Natl Acad Sci USA 97:8629-8634.

Parra P, Gulyas AI, Miles R (1998) How many subtypes of inhibitory cells in the hippocampus? Neuron 20:983-993.

Pasti L, Zonta M, Pozzan T, Vicini S, Carmignoto G (2001) Cytosolic calcium oscillations in astrocytes may regulate exocytotic release of glutamate. J Neurosci 21:477-484.

Porter JT, McCarthy KD (1996) Hippocampal astrocytes in situ respond to glutamate released from synaptic terminals. J Neurosci 16:5073-5081.

Puro DG, Stuenkel EL (1995) Thrombin-induced inhibition of potassium currents in human retinal glial (Muller) cells. J Physiol (Lond) 485:337-348.

Regehr WG, Tank DW (1990) Postsynaptic NMDA receptor-mediated calcium accumulation in hippocampal CA1 pyramidal cell dendrites. Nature 345:807-810

Regehr WG, Connor JA, Tank DW (1989) Optical imaging of calcium accumulation in hippocampal pyramidal cells during synaptic activation. Nature 341:533-536.

Sadoul K, Berger A, Niemann H, Weller U, Roche PA, Klip A, Trimble WS, Regazzi R, Catsicas S, Halban PA (1997) SNAP-23 is not cleaved by botulinum neurotoxin $\mathrm{E}$ and can replace SNAP-25 in the process of insulin secretion. J Biol Chem 272:33023-33027.

Shen K-Z, North RA (1992) Muscarine increases cation conductance and decreases potassium conductance in rat locus coeruleus neurones. J Physiol (Lond) 455:471-485.

Sontheimer H, Waxman SG (1993) Expression of voltage-activated ion channels by astrocytes and oligodendrocytes in the hippocampal slice. J Neurophysiol 70:1863-1873. 
Strubing C, Krapivinsky G, Krapivinsky L, Clapham DE (2001) TRPC1 and TRPC5 form a novel cation channel in mammalian brain. Neuron 29:645-655.

Tominaga M, Wada M, Masu M (2001) Potentiation of capsaicin receptor activity by metabotropic ATP receptors as a possible mechanism for ATP-evoked pain and hyperalgesia. Proc Natl Acad Sci USA 98:6951-6956.

Ubl JJ, Reiser G (1997) Characteristics of thrombin-induced calcium signals in rat astrocytes. Glia 21:361-369.

van Hooft JA, Giuffrida R, Blatow M, Monyer H (2000) Differential expression of group I metabotropic glutamate receptors in functionally distinct hippocampal interneurons. J Neurosci 20:3544-3551.

Ventura R, Harris KM (1999) Three-dimensional relationships between hippocampal synapses and astrocytes. J Neurosci 19:6897-6906.

von Kugelgen I, Wetter A (2000) Molecular pharmacology of P2Yreceptors. Naunyn Schmiedebergs Arch Pharmacol 362:310-323.

Wieraszko A, Goldsmith G, Seyfried TN (1989) Stimulation-dependent re- lease of adenosine triphosphate from hippocampal slices. Brain Res 485:244-250.

Wilhelm A, Volknandt W, Langer D, Nolte C, Kettenmann H, Zimmermann $\mathrm{H}$ (2004) Localization of SNARE proteins and secretory organelle proteins in astrocytes in vitro and in situ. Neurosci Res 48:249-257.

Wilhelmsson U, Li L, Pekna M, Berthold CH, Blom S, Eliasson C, Renner O, Bushong E, Ellisman M, Morgan TE, Pekny M (2004) Absence of glial fibrillary acidic protein and vimentin prevents hypertrophy of astrocytic processes and improves post-traumatic regeneration. J Neurosci 24:5016-5021.

Zhang JM, Wang HK, Ye CQ, Ge W, Chen Y, Jiang ZL, Wu CP, Poo MM, Duan S (2003) ATP released by astrocytes mediates glutamatergic activity-dependent heterosynaptic suppression. Neuron 40:971-982.

Zimmermann H (1994) Signalling via ATP in the nervous system. Trends Neurosci 17:420-426.

Zimmermann H (1999) Two novel families of ectonucleotidases: molecular structures, catalytic properties and a search for function. Trends Pharmacol Sci 20:231-236. 